This item was submitted to Loughborough's Research Repository by the author.

Items in Figshare are protected by copyright, with all rights reserved, unless otherwise indicated.

\title{
Connecting the equals sign
}

PLEASE CITE THE PUBLISHED VERSION

http://dx.doi.org/10.1007/s10758-006-9107-6

PUBLISHER

(C) Springer

VERSION

AM (Accepted Manuscript)

LICENCE

CC BY-NC-ND 4.0

REPOSITORY RECORD

Jones, lan, and Dave Pratt. 2019. "Connecting the Equals Sign”. figshare. https://hdl.handle.net/2134/8613. 
This item was submitted to Loughborough's Institutional Repository (https://dspace.lboro.ac.uk/) by the author and is made available under the following Creative Commons Licence conditions.

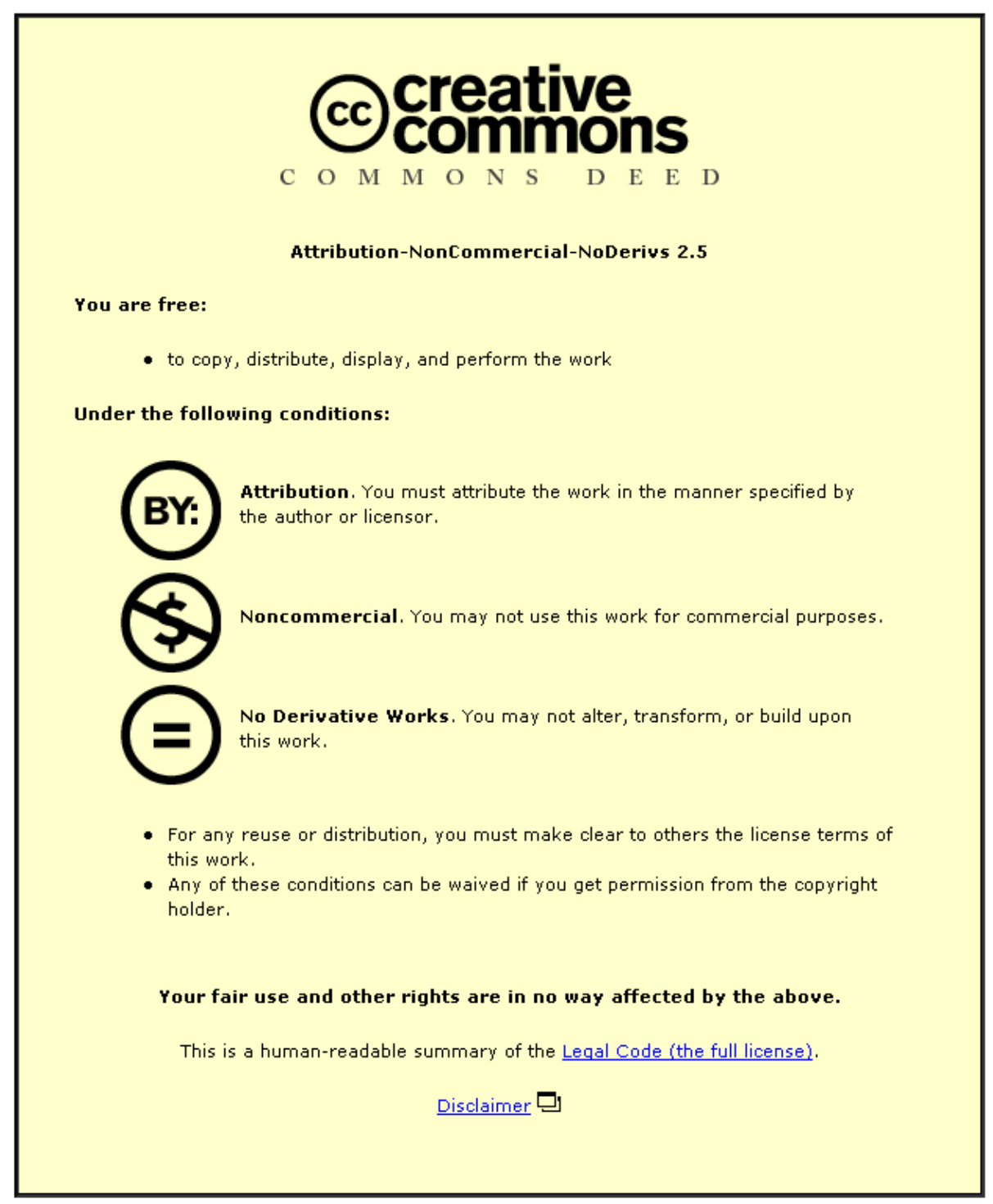

For the full text of this licence, please go to: http://creativecommons.org/licenses/by-nc-nd/2.5/ 
Editorial Manager(tm) for International Journal of Computers for Mathematical Learning Manuscript Draft

Manuscript Number: IJCO75R1

Title: Connecting the Equals Sign

Article Type: Original Research

Section/Category:

Keywords: equals sign, equivalence, microworld

Corresponding Author: lan Jones,

Corresponding Author's Institution:

First Author: Ian Jones

Order of Authors: Ian Jones; Dave Pratt; lan Jones; Dave Pratt

Manuscript Region of Origin:

Abstract: Children tend to view the equals sign as an operator symbol bereft of the rich relational properties of equality statements. It has been argued by some that this restricted view of the equals sign is due to cultural or cognitive factors. We suggest a significant factor is that rich relational meanings lack relevance within the context of paper-based arithmetic. One possible way to allow learners access to relational meanings is through interaction with technologically supported utilities for the equals sign. We report upon a trial in which two students draw on existing and emerging notions of mathemtical equivalence in order to connect an onscreen $=$ object with other arithmetical objects. 
Running head: Connecting the Equals Sign

Article type: Original Research

Title: Connecting the Equals Sign

Authors: Ian Jones*, Dave Pratt

Affiliation: Centre for New Technologies Research in Education (CeNTRE), The University of Warwick

Correspondence: Ian Jones, University of Warwick, Coventry, CV4 7AL, United Kingdom; Tel: (+44) 02476 523813; Fax: (+44) 024765 23834;

I.Jones@warwick.ac.uk

Abstract. Children tend to view the equals sign as an operator symbol bereft of the rich relational properties of equality statements. It has been argued by some that this restricted view of the equals sign is due to cultural or cognitive factors. We suggest a significant factor is that rich relational meanings lack relevance within the context of paper-based arithmetic. One possible way to allow learners access to relational meanings is through interaction with technologically supported utilities for the equals sign. We report upon a trial in which two students draw on existing and emerging notions of mathemtical equivalence in order to connect an onscreen $=$ object with other arithmetical objects.

Keywords. equals sign, equivalence, microworld 
Early records of the use of the equals sign appear to have been based on the notion of equivalence between two entities. The originator of the familiar horizontal parallel lines was Robert Recorde whose reasoning is revealed in The Whetstone of Witte, published in 1557:

"I will sette as I doe often in woorke use, a paire of paralleles, or Gemowe [twin] lines of one length, thus: $====$, bicause noe .2 . thynges, can be moare equalle.”(cited in Cajori, 1923, p.167).

In modern mathematics a variety of use-meanings are in currency. Often the symbol = is used as a place-holder for the result to a numeric calculation, as in $2+2=4$ (Behr, Erlwanger and Nichols, 1976), or to indicate that both sides have the same value, as in $2+2=3+1$ (Kieran, 1981). Within algebra the equals sign can indicate assignment as in $n=13$; or indicate sameness for all values of a variable as in $2(x+3)=2 x+6$; or draw attention to specific values of a variable that produce equality as in $x+13=2 x+15$ (Hewitt, 2006). Digital technology has widened the use-meanings of the equals sign beyond those afforded by static media. On traditional calculators = appears on a button pressed to get the result to a programmed sequence of numbers and operators. Within computer programming languages = can assign values or compare two inputs and return a Boolean result.

In this paper we track two students' articulations during a series of arithmetical tasks in order to identify how they use the equals sign and how that usage evolves. We relate those changes to the novel use of technology in this experiment. 


\section{CHILDREN'S PERCEPTIONS OF THE EQUALS SIGN}

It is widely reported that children attend to answer-getting conceptions of the equals sign when working with arithmetical notation. This observation often arises from analyses of children's responses when presented with equality statements of various syntaxes. For example, Behr et al. (1976) found in non-structured clinical interviews of six to twelve year olds that

"There is a strong tendency among all of the children to view the = symbol as being acceptable in a sentence only when one (or more) operation signs $(+,-$, etc) precede it. Some children, in fact, tell us that the answer must come after the =." (p.10)

The children in their study readily judged the truth or falsity of statements such as $2+3=5$ and $2+3=7$ whereas statements such as $8=5+3$ and $6=4+1$ were deemed to be "backwards" (p.2). The children volunteered reformulations of the latter syntaxes such as reading $8=5+3$ as " 5 plus 3 equals 8 " and writing a zero on the end of $6=4+1$ to give $6=4+10$ and reading it as " 6 and 4 makes 10 " (p.3). Statements lacking operators, such as $3=3$, were deemed incomplete and the children volunteered fixes that included $0+3=3$ and $3+={ }_{6} 3$ and $3-3=0$; and fixes for $3=5$ that included $3-5=0$ and $3+{ }_{8} 5$ and $2+3=5$ (p.4). Statements with operators on both sides of the equals sign were transformed to conform to the expectation of an answer on the right hand side. Thus some of the children changed the statement $2+3=3+2$ into the statement pair $2+3=5$ and $3+2=5$ (p.8) or 'extended' it to become $2+3+3+2=10$ (p.9). 
Behr et al.'s original research question for their study was to establish whether "children consider equality to be an operation or a relation" (p.10) and they conclude the former on the basis of the above and similar evidence. Since then their results have been replicated by other researchers (see for example Carpenter and Levi, 2000; Kieran, 1981; SaenzLudlow and Walgamuth, 1998; Theis, 2004) with children in their first year of schooling through to high school students. Much of this research considers children who accept only equality statements of the syntactical form expression $=$ number (where expression is a number-operator string) to have an operator conception of the equals sign and those children who accept a wider range of syntaxes (namely number $=$ number and number $=$ expression and expression $=$ expression $)$ to have a relational conception. However Behr et al. make no such direct mapping between the equality statement syntaxes children accept and their meanings for the equals sign. Whereas they do indeed cite the responses of children who reject syntaxes other than expression $=$ number as evidence for an operator meaning they also cite the justifications of children who accept these syntaxes; and this is at odds with much of the subsequent literature. For example, Kieran (1981) argues that teenagers who accept $2+3=4+1$ have more of a relational view than an operator view:

"They justified [it] in terms of both sides being equal because they had the same value. The comparison that subjects were eventually able to make between left and right sides of the equal sign suggest that the equality symbol was being seen at this stage more as a relational symbol than as a 'do something signal'." (p.321 - emphasis added) 
In other words, children who see that both sides make 5 when presented with $2+3=4+1$ have a relational conception of the symbol $=$ in Kieran's view. This is consistent with many other authors but in sharp contrast to Behr et al. who argue that a child who accepts $1+2=2+1$, saying " 1 plus 2 equals 3 " and " 1 plus 2 equals 3 " (p.9) for each side respectively, has an operator conception. More generally, whereas Kieran and others interpret 'the same value' as implying a relational conception, Behr et al. interpret 'the same value' as implying an operator conception. For example, when a child responded to $\frac{6}{2}=3$ by saying "they are equal to each other, they have the same value, but that doesn't mean that they are the same number" (p.8), Behr et al. noted:

"We see that D distinguishes between the concept of equality (the same value) and the concept of sameness: to be equal does not mean to be the same. Thus, to D, $\frac{6}{2}$ and 3 are two different numbers, having the same value.” (p..8)

In fact Behr et al. offer no examples of the children in their study conceiving of the symbol $=$ as a relation. They only hint as to what a relational conception might involve, such as thinking of " $2+4$ as being a name for six" and the tendency "to reflect, make judgements, and infer meanings" involving comparisons of "two members of an equality sentence" (p.10). This sense-making interpretation of relational conceptions seems richer and subtler than a dileneation of an operator-relation dichotomy based on children's acceptance and rejection of arithmetical syntaxes. It is also congruent with Baroody and Ginsburg's (1983) observation that “to treat 'equals' as 'the same as' ... is not a full relational understanding from a mathematician's point of view" but "only a basic 
relational meaning of the 'equals' sign” (p..208 - emphasis in original). Baroody and Ginsburg point to operational knowledge structured by the properties of symmetry, reflexivity and transitivity as the key to a mathematician's conception of 'equals'.

More generally, in wider contexts than formal arithmetical notation, Piaget (1952) also offers a view of the development of mathematical relationships that is not dichotomous with operational conceptions but, conversely, "the triumph of the operation properly so called over perception" (p.55). A Piagetian relational view involves an "operational plane" (p.220), that is to say a system of symmetric (equivalence) and asymmetric (nonequivalence) reversible relations. Applied to arithmetical equality statements this would involve seeing, say,

$$
\begin{array}{r}
5=2+3 \\
4+5=2+7
\end{array}
$$

as reversible relations within an operational whole. We can readily see the given equivalence of terms due to the presence of the equals sign. We can also see that one statement can be transformed into the other, and back again, the equivalence being maintained through the reversible operation of adding 4 to each side. This is distinct from the operator-relation dichotomy in which a relational meaning of the equals sign can involve attending exclusively to the combinations

$$
\begin{aligned}
& 2+3 \rightarrow 5 \\
& 4+5 \rightarrow 9
\end{aligned}
$$




$$
2+7 \rightarrow 9
$$

and then checking the results are the same.

There is then a disparity between the richness of children's mathematical thinking in non-notational contexts and the rather barren 'answer-getting' conceptions associated with formal arithmetic. This latter is "an artifact of [children's] early arithmetic training" (Baroody and Ginsburg, 1983, p.200) due to classroom arithmetic stressing actions rather than relations. The example of how equality statements are framed in textbooks and the equals button on school calculators would seem to support this view (Ginsburg, 1989; Hughes, 1986). The net result is that arithmetic is somewhat superficial; it is concerned with reading what to do and writing down the result once it is done (Hewitt, 1998). The equals sign in particular is rendered partially redundant in the process of doing arithmetic (Jones, 2006a); its role is merely that of a place-holder for the answer, perhaps analogous to a full stop added to the end of a sentence after it has been composed on the page. In fact this partial redundancy is hinted at by Behr et al. (1980) who note that operator conceptions are inherent to arithmetical notation per se rather than specifically the equals sign:

"Even in the absence of the $=$ symbol and the box, $2+4$ serves as a stimulus to do something" (p.13).

As a result arithmetical statements consist of sequences of actions punctuated by full stop-like equals signs (Hewitt, 2003b). Notation possesses a left-to-right granularity when read by a learner and an equality statement is a "temporal event, corresponding to a verbal left-right reading" conceived as "an accumulation of items and operations 
processed over time" rather than "a static state" conceived as "a whole, in one instant" (Pirie and Martin, 1997, p.160). Evidence for this can be seen in running (non-equality) statements, such as " $15+20=35+5=40+1=41$ " (Saenz-Ludlow and Walgamuth, 1998, p.165), reportedly produced by children at all ages of schooling. Given this perspective, it seems the symbol $=$ is not so much an instruction to start an operation as to halt the current operation and write down a result.

Some researchers highlight the stubbornness and barriers to further learning associated with the equals sign. McNeil (2004) calls this phenomenon change-resistance, which is the notion that "children construct knowledge on the basis of their early experiences with arithmetic operations and that this knowledge contributes to children's difficulties with more complex equations" (p.938). In a study of first grade children, Theis (2004) found that "it seems possible to make children change their conception of the equals sign, under certain conditions" but that "they are reluctant to do so and try to stick with their initial conception" (p.140). Kieran (1981) suggests it would be reasonable to assume that "later exposure to equality sentences involving the commutative and associative properties might broaden the elementary school child's notion of the equals sign. However, this does not seem to be the case." (p.318). Kieran contends that "the procedures used by students to solve equations and to find the derivative of a function would seem to indicate that high school and college students may also tend to interpret the equals sign in terms of an operator" (p.325). 
In addition to these issues of classroom culture, cognitive stubbornness and barriers to progression it is insightful to consider conceptions of the equals sign, and arithmetical notation in general, in terms of relevance theory (Wilson and Sperber, 2004). Although typically associated with verbal communication, the pragmatic concept of "relevance" as "assessed in terms of cognitive effects and processing effort" (p.609), where the greater the effect-to-effort ratio the greater the relevance, can be applied here. The common usage of arithmetic, whether in classrooms or on the back of an envelope, is to produce a result - this is almost invariably the desired effect of doing arithmetic. The most efficient, least effortful way to achieve this is rarely through exploiting the symmetric, reflexive and transitive properties of properly formed equality statements. Instead most people process a sequence of numbers and operators one-by-one then write down the result, often employing the cultural convention of the symbol = for perceptual clarity. While inspiring approaches to teaching arithmetical equality have been demonstrated (e.g. Pirie and Martin, 1997) and suggested (e.g. Baroody and Ginsburg, 1983) we might suspect that drawing attention to the operational (Piagetian) properties of equality statements will always be an overly-contrived endeavour, full of forced irrelevancy. Indeed, given the encumberances that arithmetical conventions are reported to cause learners and teachers of algebra (Filloy and Rojano, 1989; Kieran, 1981; Knuth, Stephens, McNeil, and Alibali, 2006) we might step back and ask why teach arithmetical notation at all?

However we contend that formal arithmetic should be taught; and that it should be taught in such a manner that makes the richest possible meanings of mathematical 
equivalence relevant to the learner. This is consistent with Hewitt's (2003a) contention that notation should be taught as a subject unto itself. However, given that it is in the nature of static paper-based media for the arithmetical role of the equals sign to be that of a mere 'result prompt' how can richer conceptions of equality statements be made relevant?

We believe the answer may lie in technologically supported arithmetical systems. Students may construct new meanings for symbols by observing and engaging with the actions triggered through that computational power. Learning through use of symbols in this way is not necessarily unique to computer-based environments but it is not difficult to understand how such learning can more easily be facilitated by digital technology than conventional media. Papert (1996) has referred to this potential as the Power Principle (and Noss and Hoyles, 1996, as Using before Knowing), whereby students are empowerd to learn through use in contrast to conventional approaches in which the student is typically expected to know the mathematics before it can be effectively used. Yerushalmy (2004) has also presented examples in which technology has transformed student learning through supporting the curriculum in a manner not possible without technology.

We are not suggesting that technology of itself guarantees richer meanings of the equals sign: consider how a traditional school calculator reinforces answer-getting conceptions. Nor do we suggest that technology necessarily guarantees the relevancy of any richer meanings that are supported. In a study into children's interactions with a variant on the 
traditional school calculator, called Equivalence Calculator, in which an answer-getting utility of the $=$ button is replaced with a value-comparing utility, children made little use of the equals sign suggesting they found the = button irrelevant to the tasks at hand (Jones, 2006b). Nonetheless, carefully designed and technologically supported mathematical environments offer the potential for $r e$-visioning how arithmetical notation is taught in the classroom.

It is worth noting how these complex and subtle issues inform our epistemological approach to thinking about the evolution of conceptions associated with the equals sign. We advocate a perspective in which various meanings can be held simultaneously though with varying priorities. Accordingly, we are using a theoretical framework based on diSessa (1988), in which knowledge is seen as made up of a multitude of small pieces, which gradually become connected through learning. Different sense-making contexts can trigger different pieces of knowledge. Experience of the power and consistency of any particular piece of knowledge to make sense of a situation can render that piece of knowledge more or less useful. Priorities are allocated to pieces of knowledge according to how powerful they have been in prior processing. In this framework, children may hold simultaneously both the operation and relational meanings for the equals sign, but they may have attached low priorities to the realtional meaning and the pedagogic challenge would be to find a setting in which the relational meaning is more directly useful as it is seen in practice to be a powerful sense-maker. Alternatively, the students may simply only hold the operator meaning in which case the setting needs to help the students construct a new meaning, that of equivalence relations, 
out of their current knowledge state. Either way, it seems from the literature that many students attach a high priority to the various operator meanings for the equals sign. The pedagogic challenge can thus be restated as one of developing resources that reinforce the relational meaning either so that such a meaning can be invented by the student or so that the associated priority is increased for certain types of situations.

\section{APPROACH}

In the spirit of the constructionist movement (Harel and Papert, 1991) we aimed to place the students in the position of building an object, emphasising engagement with the aspiration that the students would take control and feel ownership for the task. In designing a task that fitted this approach, we also wished to pay attention to the planning paradox (Ainley, Pratt, and Hansen, 2006) where task design is liable to pursue purpose at the expense of curriculum focus or vice versa. We therefore searched for a task that was likely to feel purposeful and yet likely to lead to a sense of utility for the equals sign. We chose to use a microworld, written in Imagine $\operatorname{Logo}^{1}$ (a very powerful version of Logo), and designed to enable teachers and students to explore and connect the multiple representations of fraction. The microworld is described below.

We hoped that observing the children's activity with the microworld would provide window onto children's thinking-in-change (Noss and Hoyles, 1996). We expected that the mouse-clicking activity within the microworld would be coupled with the children's speech to offer insights into students' thinking-in-change about fractions. In fact, when 
we looked through this window, what we saw were examples of students' thinking-inchange about the functions of the equals sign.

The researchers acted throughout as participant observers, responding with help to technical questions, probing to draw out understanding of the children's actions and occasionally prompting further activity through challenging interventions. The transcripts were written up as a relatively direct and uninterpreted account in which every effort was made to set out what happened in as clear a way as possible.

Subsequently, an interpreted account was developed which allowed conjectures that might explain that activity. Central issues were identified through discussion between the researchers and further accounts developed that emphasised those issues. This whole analytical approach was consistent with the notion of progressive focussing (Robson, 1993).

\subsection{The Visual Fractions Microworld}

The Visual Fractions ${ }^{1}$ (VF) microworld was developed as an interactive fractions environment in which children and teachers can work with prepared activities or use provided development tools to create and modify activities of their own. The authors of this paper were not involved in the development of VF but in the trialling of the final iterative version before its commercial release.

Quasi-concrete objects. VF allows learners to work with on-screen mathematical objects including representations of fractions (numerical and graphical) and arithmetical 
symbols $(+, \times,=$ and so on). Such mathematical objects have been described as quasiconcrete (Turkle and Papert, 1991) because they populate a two dimensional space in which they can be created, modified, destroyed, moved and connected through direct manipulation. The power of quasi-concrete objects has been detailed by Turkle and Papert:

[a quasi-concrete object] might be defined by the most formal of rules and so be like a construct in pure mathematics; but at the same time it is visible, almost tangible, and allows a sense of direct manipulation that only the encultured mathematician can feel in traditional formal systems (p.162) ... You can see them, move them, put one on top of another. But at the same time, they are abstract and mathematical. Ambivalent in their nature, computational objects can be approached in different ways. Hard-approach programmers treat a sprite more like an abstract entity - a Newtonian particle - while soft-approach programmers treat it more like a physical object - a dab of paint or a cardboard cutout (p.179)

Static symbols can therefore take on a life of their own, what Papert (1993) calls a Protean quality, when transferred to the screen. Whereas on paper the equals sign might simply be a place-holder or else indicate that the reader should carry out some mental operation, on screen the equals sign can be designed to carry out that action for you. In this respect, the computer-based symbol has a power not associated with its paper-based equivalent.

The quasi-concrete objects populating VF have one or two input ports. For example the equals sign, in common with many programming languages, takes two inputs and returns a Boolean result. Figure 1 displays an equals sign with two non-equivalent inputs (input ports appear as small diamonds above objects). The inputs 'percent1' (i.e. the $40 \%$ 
object) and 'fraction1' (i.e. the $1 / 2$ object) as well as the Boolean result 'false' can be seen written above it. Note that the numbers written above each object (45, 80 and 54 in Figure 1) are simply resizing tools and are not of concern here.

\section{Figure 1}

Along with the equals sign VF provides another object, called a region, which also takes two inputs and returns a Boolean result. Unlike equals signs, regions possess just one input port and the comparison is made with whatever is physically placed within the region. Thus the equivalent situation to Figure 1 using a region rather than $=$ would be that shown in Figure 2.

\section{Figure 2}

Regions provide more flexibility than equals signs because more than one object can be placed within them (Figure 3). Users can select a rule for comparing the input port value with the contents of the region such as 'sum of all terms' or 'any term' or 'all terms'.

\section{Figure 3}

VF also provides a flag object whose function is purely perceptual. Flags can be connected to equals signs and regions in order to display their Boolean state more visibly (without a flag, an equals signs displays its Boolean state in text and a region does not display its state). A 'false' input to a flag produces a sad face and a 'true' input produces a happy face (Figure 4). 


\section{Figure 4}

Unlike many programming languages the assignment of values in VF does not use an equals sign. Rather, a number's input port can be connected to another number. For example, in Figure 5 the percentage object takes its input from the fraction object.

\section{Figure 5}

It is worth clarifying that such input connections are unidirectional. In Figure 5 changes

to the $\frac{1}{2}$ object would cause corresponding changes to the $50 \%$ object but not vice versa.

In fact the value cannot be adjusted so long as a number object's input port is occupied.

Figure 6a followed by Figure 6b display how connections are directly manipulated through connecting an input port to an object. This design decision is mathematically arbitrary and might as easily have involved starting with the object. We can imagine some learners may find this port-to-object (rather than object-to-port) construction intuitive and others may find it counter-intuitive.

\section{Figures $6 a$ and $6 b$}

VF also supports operator symbols, such as the plus sign, which take two inputs and return a numerical result. In Figure 7 the + is connected to $\frac{1}{2}$ and $\frac{1}{4}$ and returns $\frac{3}{4}$ (which can be seen written above it).

Figure 7 
'Equals' in VF. Given this overview we might pause and consider what meanings for 'equals' associated with the symbol $=$ are supported in VF. The first thing to note is that $=$ may merely be placed on screen and left disconnected from other symbols and so functionally redundant. The second is that when connected the function of $=$ is as a comparator of numbers producing a Boolean output. These numbers may appear directly onscreen as fractional representations or as results of operations from the symbols,$+ \times$ and so on. The third is that regions provide an alternative way to make comparisons. Regions are more flexible than equals symbols as they allow comparisons involving multiple inputs and a variety of settings. Finally the Boolean output of $=$ and generally connectivity of arithmetical symbols in VF allows for the construction of larger webs of objects than single equality statements. An interactive web might be built that incorporates multiple number, operator and relational objects. There is scope then to construct and explore a 2D Piagetian operational plane of equivalence and nonequivalence reversible relations.

The setting and tasks. The two girls, $\mathrm{C}$ and $\mathrm{L}$, in this experiment were aged 13 years. They were confident and capable with mathematics and computing. The activity lasted 80 minutes and was recorded using a microphone and screen capture software.

The students were introduced to some basic objects and the possibility of making connections. No description or utility of the objects was given. They were then challenged to design a task that might help primary children learn about the equivalence of fractions. Subsequently they were asked to design a task to help children learn about 
fracrion arithmetic. In the curriculum for England and Wales, children of this age practice fraction arithmetic and so the task involved using numerical skills that they had encountered and practiced in class. Finally, the girls freely explored the remaining tools.

Overview of the Products of the Students' Activity. Before describing in detail how the students' articulations of the equals sign evolved, it will be useful to the reader to appreciate what the students produced overall. The students designed a task that allowed users to match a picture representation, chosen from the five options on the right hand side, with a numerator-denominator equivalent (Figure 8). One example has already been completed. The girls decided to incoporate flags to provide feedback once a picture representation had been dragged to the adjacent region (the flag would display thumbsup or down to indication true or false).

Figure 8

A researcher introduced the addition operator and asked the students to investigate its connector ports. After practicing a little they were challenged to design a task for their classmates of the same age. They designed an arithmetic task in which users were required to correct answers to expressions (Figure 9). Again their design utilised feedback in the form of flags.

\section{Figure 9}

The students went on to freely explore other tools available on the panel, mostly further representations of fractions (Figure 10). 
Figure 10

\section{FINDINGS ON INTERACTIONS WITH THE EQUALS SIGN}

Having described the microworld itself and given an overview of what the two students produced we now describe how the activity provided a window onto their thinking-inchange in relation to the equals sign.

Orientation. At the start of the trial, when the girls were exploring various on-screen number objects, a researcher (RI) drew attention to objects' input ports. C connected a square object to a fraction object (Figures 11a and 11b).

Figures $11 \mathrm{a}$ and $11 \mathrm{~b}$

Following this RI asked C what had happened.

1. C: It changes the squares into 3 quarters, with 3 quarters of it shaded.

2. RI: Yeah, it's changed to it. What do think would happen, L, if you were to change the 3 quarters to a different fraction?

3. L: Would it change automatically?

L then tested her suggestion by changing the numerator to 4 then increasing the numerator stepwise up to 12 (Figure $12 \mathrm{a}$ ). When she reached $\frac{4}{13}$ the square object became a question mark (Figure 12b). It is interesting to note that $\mathrm{L}$ offered a sophisticated mathematical explanation for this quirk: 
4. L: It won't go any higher. If you go over 12 it doesn't.

5. RI: Keep going up. See if you're right.

6. L: It doesn't do 13, 17 .

7. RI: What doesn't do?

8. L: Prime numbers. $13,17,19$

9. RD: Why prime numbers?

10. L: Because they only go to 13 and then one. Doesn't go into anything else. Goes up to 20 .

Figures $12 a$ and $12 b$

Following this the girls were asked if it works "the other way; if you change the square does the fraction get updated?" After a little experimentation (trying to adjust the square object's dimensions, marked 4 and 3 in Figure 12a) L established the unidirectionality of connections and replied no. The girls were then directed to experiment with regions and flags and went on to construct the fraction comparators shown in Figures 13a and 13b.

Figures $13 a$ and $13 b$

Incorporating the Equals Sign. The girls were then prompted to design an activity to help younger children learn about fractions. C suggested the following activity:

11. C: You could put the fraction down one side of the page here and then put pie charts filled in and you've got to match them up. Put it in a region and see if it's the same. 
This involved their first employment of the $=$ object (Figure 8), which arose when C suggested:

12. C: Perhaps we should put like an equal sign or something?

They did not connect the = object to any other objects when constructing this activity, the functional comparison between two fractions was implemented instead by connecting regions to fractions and flags (Figure 14). The equals sign here was used as a perceptual indicator, or 'syntactic glue', between a fraction and an equivalent representation of the fraction. Consistent with some researchers (e.g. Carpenter and Levi, 2000; Kieran, 1981) this usage of number $=$ number syntax, as opposed to expression $=$ number, might be deemed a move from an operator notion to a relational notion of the symbol $=$. However the girls followed a left-to-right grain in constructing these equality statements, starting (in Figure 14) with $\frac{1}{2}$ then $=$ then the region then the flag, and then exploiting the functionality of the region and paying no more attention to the equals sign. It seems then that = was partially redundant for the girls and provided merely a visual connection between one term and another rather than an active relation between the two terms.

Figure 14

Connecting the Equals Sign. Following this the girls were directed to explore the operator objects $(+,-$ and so on). They went on to construct a second activity for younger children to learn about fractions (Figure 9). We now describe how they shifted from 
placing the $=$ object onscreen as a disconnected visual prompt (above) to employing it as a functional element of equality statements.

Initially the girls placed two fractions and an operator onscreen. A researcher drew their attention to the input ports and encouraged them to experiment. The girls immediately connected the fractions as inputs to the + object as in Figure 15 (the curved arrows have been added to screen excerpts for the purposes of clarity but were not on screen at the time. They represent the relation 'takes the input'.)

\section{Figure 15}

Next the students placed an = object on screen, rather than a region as previously, and discussed possible connections.

13. L: Put the equals and connect like that, on to the 8 .

14. C: No don't you connect it on to the add?

15. L: The plus yeah.

L appeared to believe that the equals sign should be associated with the second addend and was perhaps attending to the left-to-right grain of equality statements. C disagreed and suggested connecting the equals sign 'on to the add' and arguably attended to a 'flow of data' starting with the addends, through the operator and onto the equals sign (Figure 16). We have here the first indication of the technological setting drawing C's attention to the functional nature of the = rather than its purely perceptual role. It is also 
interesting to note her metonymical use of the word "add" for both the symbol + and the result of the process of combining the addends.

\section{Figure 16}

Figure 16 captures L attempting to drag the other equals connector to empty space:

16. L: I don't know where you connect that.

17. C: No you leave that one...put a box or something.

18. L: We really need to put a region.

In lines 16-18 the girls expressed the need for a right-hand connection for the equals sign and decided upon using a region in which they placed a fraction after working out the answer (Figure 17).

\section{Figure 17}

It is interesting to note that $\mathrm{C}$ had confidently stated how she thought the operator should be connected but that the connections from the equals sign had arisen experimentally.

Figure 17 suggests the +'s connectors had, to some extent, been perceptually repeated for the $=$. This may be partly due to the software constraining connecting $=$ in a way that is parallel to that of operators and partly due to a sense of data-flow coming to be prioritised over a sense of left-to-right grain

Next the girls placed a flag onscreen and tagged it on to the right hand end of the equality statement (Figure 18). The functional role of the equals sign as that of a 
relationship between the process on the left and the result on the right can be seen. However the input for the flag is the result (or at least the region containing the result) rather than the equals sign. It seems that the girls were expecting the comparison utility of the region (c.f. Figures 13a and 13b) to act as an input for the flag rather than that of the $=$ object. However, it so happens they had connected the objects such that the region had no input and was in fact technically redundant.

\section{Figure 18}

The girls had expected the flag to be positive (smiley face) and tried dragging the result object in and out of the region a few times but to no avail. They experimented through trial and error with the connections, including repeatedly trying to attach the result object to the + object and then to the $=$ object but still the flag did not change state. They had hit an impasse and could no longer progress by doing simply that which objects' input ports afforded. Finally a researcher suggested that they try without using the region and the students deleted it (Figure 19).

\section{Figure 19}

They connected the addends as inputs to the operator again and set the result to $\frac{13}{6}$.

19. C: Smiley face isn't connected to anything.

20. L: Connect that (face) to the right answer. 
L's suggestion that they connect the flag to the result was disallowed by the software. C concluded that the reason it would not connect was because the result was "not connected" to the equals sign, which in turn was "only connected to the plus". This again hints towards the technology affording a data-flow conception over a left-to-right conception. However when they tried to connect the result to the equals sign the software would not allow it (Figure 20).

\section{Figure 20}

With further trial and error L connected the free = object input port to the plus sign and the flag to the equals sign, producing the situation in Figure 21.

\section{Figure 21}

When the flag became true the students believed that they had succeeded. A researcher suggested that they change the answer to test it. They re-set the result to $\frac{13}{7}$ and the flag still showed true. The students laughed and then tried a few things starting with a disallowed attempt to connect the answer to the flag. The experimental nature of their trials is evidenced by dialogue.

21. L: Maybe that $[\mathrm{rhs}=$ object port $]$ needs to be on the other side.

22. C: This [result] isn't connected to anything.

23. L: Perhaps if you do that [result] to the smiley face. Or try it to the equals.

24. C: Perhaps that [result] connected to the equals. 
When they finally connected the flag to the equals sign it changed to true but $\mathrm{C}$ said:

25. C: It's just got its thumbs up to the equals. It's always right.

They attempted to connect the flag to the answer and when this did not work connected the equals sign to the result (Figure 22).

Figure 22

A researcher asked what was written above the equals sign [i.e. the Boolean result 'true'].

26. C: It says true. But we don't know what.

The girls attempted to connect the flag to the answer yet again, as though attending to the left-to-right grain once more. It seems that the students did not conceive of a mathematical but rather a technological sense of the word 'true' written above the equals sign.

27. C: So if [the equals sign is] connected to [the answer] we just need to connect [the flag] somewhere.

C momentarily dragged the flag's connector round the screen and placed it on the equals sign. This circuitous route suggested her choice of where to place the connection was somewhat experimental and playful. The flag became true. L suspected they had repeated the situation in Figure 21 in which the flag said true whether the result was correct or not. 
28. L: He still always has his thumbs up.

The students tested the equation by changing the result to an incorrect value to see the effect on the flag. The flag displayed false (Figure 23).

29. C: It's worked now because look it says now. There, that's done it now.

\section{Figure 23}

A researcher asked the students to explain what they had done (RD refers to the second author):

30. L: I think I connected the equals signs straight to the smiley face instead of connecting it to the answer.

31. C: You've got the equals answer to the plus and then you've got it to the fraction, then you've got a smiley face to the equals.

32. L: So there's like a circuit there...

33. C: ...between them three so if you change a fraction there it will go wrong.

The emerging sense of data-flow through the quasi-concrete objects on the screen was explicated in line 32 as "like a circuit". In fact this 'circuit' is implicitly described in terms of = as the "hub' for a network incorporating "the plus", "the fraction" and "a smiley face" (line 31). It is also interesting to note C's use of the compound term "equals answer" for the equals sign hinting at the presence of the notion of $=$ as a signal for the result. This notion sits alongside the girls' emerging technologically-afforded conceptions of an equality statement as a data-flow circuit. 
The girls went on to create another similar equality statement, namely $\frac{2}{3}+\frac{11}{9}=3 \frac{8}{18}$ in Figure 9 without any difficulty whatsoever. However the third statement in Figure 9, namely $\frac{2}{5}-\frac{2}{10}=\frac{1}{5}$, did cause them some notable difficulties. C suspected a technical constraint: "Don't think you can do a negative [result]"; and was indeed correct that VF does not support assigned number objects. Their problems here arose due to not attending to the non-commutativity of subtraction and the corresponding flag displaying not 'true' or 'false' but 'unknown' (due to VF not supporting negative results). However, rather than attend to the mathematics they attended emperically to the connections between onscreen objects:

34. L: Is it connected still?

35. C: I think because we changed it.

36. L: They're both connected up [operands].

37. C: Let's do this again [operator dependencies] Still isn't working. I think we'll have to get rid of 2 connections.

38. L: Yes.

39. C: Now connect those 1 st, connect this to the answer.

40. L: Then that to the takeaway.

41. C: This to the answer. Then that to the equals. Still thinking [face].

42. L: Do you have to. 
43. C: Let me try something.

44. L: No. It goes to the equals.

45. C: How do we do that before?

46. L: They're [other faces] both connected to the equals.

Through further experimentation the equality statement became $\frac{2}{5}-\frac{5}{15}=\frac{1}{15}$ and the flag displayed 'true'. A researcher intervened to draw their attention to why this worked yet $\frac{2}{5}-\frac{7}{15}=\frac{1}{15}$ had not.

47. RI: Put it back to what was before. What's different?

48. C: Oh because did 2 ths and that would make 6 fifteenths, 6 takeaway 7 would be minus 1 and it didn't seem to do minuses.

Later still in the trial the girls went on to explore the other fraction objects supported by VF (Figure 10). It is notable that the girls effortlessly constructed both the equality statements shown in Figure 10 except for the connection between the $=$ symbol and the result. Rather than directly set the result as an input to $=$ they first attempted to set $=$ as an input to the result. Whereas before this had caused a significant impasse this time they quickly went about trying the other way round with immediate success.

\section{DISCUSSION}


The above episode allows us to identify how the students' conceptions of the equals sign appeared to change during the activity. The authors fully appreciate that a single case study is limited in the general insights it may bring. In light of this we will discuss prior and emergent associations with $=$ during the trial against the the existing literature with emphasis on the features we consider unique to this case.

It is worth noting that the girls only produced two syntaxes; number $=$ number and expression $=$ number. As would be expected from the literature they did not volunteer number $=$ expression nor expression $=$ expression forms - despite being confident mathematicians. However the interest here is not on syntax variations but the sense in which the software allowed the children to open the lid on equality statements to get them working or to repair them when they did not. Such constructing and mending activities have been shown to be of value in providing opportunities for learners to purposefully utilise mathematical ideas (Ainley et al., 2006).

\subsection{Early Meanings}

Relational thinking. According to Behr et al. (1976), relational conceptions are not present if (say) $\frac{6}{2}$ and 3 are seen as different numbers (albeit of the same value) rather than as synonyms for the same number. The girls revealed some subtle thinking about the relationships of symbols when, during the early phase of the trial, they referred to various representations (squares, fractions and so on) as "the same" (line 11) rather than as having the same value. Further examples of this include referring to an onscreen 
square as "the third", an onscreen circle as "one fifth" and so on. Note, however, that this flexible interchangeability of symbols by no means indicates a full grasp of relational thinking such as that outlined by Piaget (1952) or Baroody and Ginsburg (1983). Nor were these relational conceptions of the onscreen symbols associated with the equals sign.

Partial redundancy of $=$. When the girls first came to employ an equals sign they did not functionally connect it to the other symbols (they used a region instead - Figure 14). Rather, = was used by the girls as an afterthought to visually indicate that the number on the left-hand side goes with the empty box on the right-hand side. In addition, when $\mathrm{C}$ says "put like an equals sign or something" (line 12) she hints that there is nothing particularly special about the symbol $=$ and that any perceptual indicator might have done. It seems that the richer relational properties of the equals sign were irrelevant and therefore redundant at this time.

Left-right grain. The girls' left-right temporal sequencing of equality statements can be seen in the syntaxes constructed (Figures 9 and 10) and in the manner equality statement symbols were built up (e.g. the progression in Figures 15 to 18). This was to be expected from the literature, and many authors would associate this with a non-relational meaning for the equals sign (e.g. Pirie and Martin, 1997; Saenz-Ludlow and Walgamuth, 1998). 


\subsection{Evolving Meanings}

Data-flow. What might be termed a data-flow conception of equality statements began to emerge during the trial. This is hinted by L's reflective use of the word "circuit" to describe completed equality statements (line 32). However, earlier in the trial, it appears to be $\mathrm{C}$ who first began attending to data-flow conceptions as contrasted against $\mathrm{L}$ who continued to prioritise the left-right grain for a while. For example, in lines 13 and 20, L feels that the way forward is to connect a given symbol to whatever is adjacent left. This resulted in several impasses in which the girls attempted to make connections disallowed by the software, such as (repeatedly) connecting results to $=($ e.g. Figure 20$)$; as well as connections technically allowed by the software but that gave 'unknown results', such as connecting flags to results (e.g. Figure 18 and line 20). In contrast, C's notion of leftright grain, while present, had a low priority. C felt that an operator should take two numbers as its inputs (Figure 15) and that an equals sign should take the left-hand side and right-hand sides as its inputs (Figure 17).

As we would expect from diSessa's (1988) "knowledge in pieces" this was no simple story of L taking one perspective and $\mathrm{C}$ taking another. There were times $\mathrm{C}$ prioritised notions of left-grain over notions of data-flow, and likewise in reverse for L. There were also times when the girls experimented through trial and error to get things working correctly and were attending to the connections of individual symbols rather than a leftright or data-flow overview of the whole equality statement (e.g. lines 21 to 24). Indeed, this flexibility to switch between exploring individual symbols' connections and 
stepping back to view the whole equation was key to enabling the data-flow conception to emerge. In fact such activities, involving working closely with quasi-concrete objects towards an overall construction, are important affordances of microworlds

Relational thinking. We have seen above that the girls used symbols as different names for the same object rather than as different objects having the same value. For example the spoken word "third", the symbol $\frac{1}{3}$ and equivalent pictorial objects were all used synonymously and interchangeably. The emergence of equality statement data-flow conceptions gave opportunities for such relational thinking to be associated with the equals sign and drawn upon in new ways. For example, C's metonymical use of the term 'add' to mean 'the result of adding those two numbers' illustrates this (line 14): by connecting two inputs to the plus sign (Figure 15) C seemed able to consider the lefthand side of the equality statement as an object, verbally labeled 'add', rather than a process the result of which goes on the right-hand side. We tentatively propose that this evidences a flowering of synonymous-type relational thinking (i.e. different names for the same thing) into proceptual-type relational thinking (i.e. one name for a process and its result - Gray and Tall, 1994). As the girls went on to construct further equality statements this more sophisticated relational approach was repeatedly apparent: the operator was first connected to two inputs and from then on the left-hand side of the equality statement was referred to in terms of the name of the operator. This enabled $\mathrm{C}$, and eventually both the girls, to attend to the left-hand side and the right-hand side as two equivalent objects when connecting inputs to the equals sign. Towards the end of the 
trial, when a researcher asked some guided questions, this evolving relational conception was evidenced in C's vocabulary:

49. RD: What are the inputs to the add?

50. C: The 2 fractions

51. RD: What are the inputs to the equals?

52. C: It's the add which is connected to both the fractions and the right answer.

53. RD: So what is the equals comparing?

54. C: It's comparing the addition of those and the answer

Operator meanings. We have seen that many authors determine children to have an operator meaning for $=$ when they focus on processing what is on the left and putting the result on the right. We have also seen from $\mathrm{C}$ and L's attendance to the left-right grain that this meaning was present in their thinking from the start of the trial. However it is interesting to note that this operator meaning became necessary to make progress (and so was prioritised again) towards the end of the trial. This occurred when the girls attempted to connect up $\frac{2}{5}-\frac{7}{15}=\frac{1}{15}$ through trial and error and attendance to data-flow conceptions (lines 34 to 46). Ultimately this led to a different expression being constructed and it was only when a researcher drew the girls' attention back to $\frac{2}{5}-\frac{7}{15}=\frac{1}{15}$ that $\mathrm{C}$ realised what the problem had been - and accordingly attended to getting and checking the result (line 48). This event highlights a key difference between 
analyses modeled on prioritised "knowledge in pieces" compared to those modeled on misconceptions being replaced by new conceptions. We would like to clarify that operator notions are not misconceptions to be replaced, but flexible ways of seeing that can be prioritised over relational meanings when it is useful to do so.

\section{CLOSING COMMENT}

The persistence of so-called misconceptions for the equals sign is entirely to be expected in a culture that promotes that type of meaning by offering tasks in which the operational meaning has utility. We can address this issue by offering greater utility to the deeper, operationalised relational meanings for the equals sign. The design of tasks that offer feedback to children, which prioritises rich mathematical meanings of the equals sign and equality statements, is non-trivial. We believe however that we have reported above one such case.

\section{NOTES}

1. Imagine has been developed by a team at Comenius University, Bratislava, Slovakia (Kalas and Blaho, 2000) and is published by Logotron. Visual Fractions has been written in Imagine and is also published by Logotron.

\section{REFERENCES}

Ainley, J., Pratt, D., and Hansen, A. (2006). Connecting engagement and focus in pedagogic task design. British Educational Research Journal. 32(1): 23-38. 
Baroody, A. J., and Ginsburg, H. P. (1983). The effects of instruction on children's understanding of the "equals" sign. The Elementary School Journal. 84(2): 198-212.

Behr, M., Erlwanger, S., and Nichols, E. (1976). How children view equality sentences No. PMDC-TR-3). Tallahassee, Florida: Florida State University.

Behr, M., Erlwanger, S., and Nichols, E. (1980). How children view the equals sign. Mathematics Teaching. 92: 13-15.

Cajori, F. (1923). A history of mathematical notations volume 1: Notations in elementary mathematics (p. 167). La Salle, Illinois: The Open Court Publishing Company.

Carpenter, T., and Levi, L. (2000). Developing conceptions of algebraic reasoning in the primary grades. Madison, WI: University of Wisconsin.

diSessa, A. (1988). Knowledge in pieces. In G. Forman, and P. Pufall (Eds.), Constructivism in the computer age (p.p. 49-70). Hillsdale, New Jersey: Lawrence Erlbaum Associates Inc.

Filloy, E., and Rojano, T. (1989). Solving equations: The transition from arithmetic to algebra. For the Learning of Mathematics. 9(2): 19-26. 
Ginsburg, H. (1989). Children's arithmetic: How they learn it and how you teach it (2nd ed.). Austin, Texas: pro-ed.

Gray, E., and Tall, D. (1994). Duality, ambiguity, and flexibility: A "proceptual" view of simple arithmetic. Journal for Research in Mathematics Education. 25(2): 116-140.

Harel, I., and Papert, S. (1991). Constructionism. Norwood, NJ: Ablex Publishing Corporation.

Hewitt, D. (2006). A reaction to 'The design of equality statements': Working as a mathematician but writing differently. Working Papers of the Warwick Suminar Group. 2: $83-88$.

Hewitt, D. (1998). Approaching arithmetic algebraically. Mathematics Teaching. 163: 19-29.

Hewitt, D. (2003a). Notation issues: Visual effects and ordering operations. Proceedings of the 2003 Joint Meeting of PME and PMENA (3: pp. 63-69). Honolulu.

Hewitt, D. (2003b). Some issues regarding formal algebraic notation. 23rd Conference of the British Society for Research into Learning Mathematics (1: pp. 31-36). Sheffield, UK. 
Hughes, M. (1986). Children and number: Difficulties in learning mathematics . Oxford: Basil Blackwell.

Jones, I. (2006a). The design of equality statements. Working Papers of the Warwick Suminer Group. 2: 63-82.

Jones, I. (2006b). The equals sign and me. Mathematics Teaching. 194: 6-8.

Kieran, C. (1981). Concepts associated with the equality symbol. Educational Studies in Mathematics. 12: 317-326.

Knuth, E., Stephens, A., McNeil, N., and Alibali, M. (2006). Does understanding the equals sign matter? Evidence from solving equations. Journal for Research in Mathematics Education. 37(4): 297-312.

McNeil, N. (2004). Don't teach me $2+2$ equals 4: Knowledge of arithmetic operations hinders equation learning. Proceedings of the Twenty-Sixth Annual Conference of the Cognitive Science Society (p.p. 938-943). Chicago.

Noss, R., and Hoyles, C. (1996). Windows on mathematical meanings: Learning cultures and computers. Dordrecht, The Netherlands: Kluwer Academic Publishers. 
Papert, S. (1996). An exploration in the space of mathematics educations. International Journal of Computers for Mathematical Learning. 1(1): 95-123.

Papert, S. (1993). Mindstorms: Children, computers and powerful ideas (2nd ed.). New York: Basic Books.

Piaget, J. (1952). Child's conception of number. London: Routledge and Kegan Paul Ltd.

Pirie, S., and Martin, L. (1997). The equation the whole equation and nothing but the equation! one approach to the teaching of linear equations. Educational Studies in Mathematics. 34: 159-181.

Robson, C. (1993). Real world research. Oxford: Blackwell.

Saenz-Ludlow, A., and Walgamuth, C. (1998). Third graders' interpretations of equality and the equal symbol. Educational Studies in Mathematics. 35: 153-187.

Theis, L. (2004). The issues of learning the equals sign for grade one students. 2004 Annual Meeting of the Canadian Mathematics Education Study Group (p.p. 135-141). Québec. 
Turkle, S., and Papert, S. (1991). Epistemological pluralism and the revaluation of the concrete. In I. Harel, and S. Papert (Eds.), Constructionism (p.p. 161-192). Norwood, NJ: Ablex Publishing Corporation.

Wilson, D., and Sperber, D. (2004). Relevance theory. In G. Ward, and L. Horn (Eds.), Handbook of pragmatics (p.p. 607-632). Oxford: Blackwell Publishing.

Yerushalmy, M. (2004). Does technology transform the content of algebra curricula? An analysis of critical transitions for learning and teaching. ICME July 2004, accessed $24^{\text {th }}$ August 2006 at http://construct.haifa.ac.il/ michalyr/Yerushalmy.pdf.

\section{LEGENDS}

Figure 1

Quasi-concrete objects in VF

Figure 2

A region object compares $40 \%$ and $1 / 2$

Figure 3

A region object compares $20 \%+20 \%$ and $1 / 2$

Figure 4

Equality statements and flag objects 
Figure 5

Value assignment

Figures $6 \mathrm{a}$ and $6 \mathrm{~b}$

Making a connection

Figure 7

Connecting the + object

Figure 8

The first activity developed by the students

Figure 9

The second activity developed by the students

Figure 10

The third activity developed by the students

Figures $11 \mathrm{a}$ and $11 \mathrm{~b}$

$\mathrm{C}$ assigns a value to a square object

Figures $12 \mathrm{a}$ and $12 \mathrm{~b}$

The square object does not support all values 
Figures 13a and 13b

The students experiment with square and flag objects

Figure 14

The students use an $=$ object

Figure 15

The students connect a + object

Figure 16

The students connect an $=$ object

Figure 17

The students attempt to construct an equality statement

Figure 18

The students connect a flag object to the answer

Figure 19

The students de-connect then reconnect

Figure 20

The students attempt to connect a number to the $=$ object 
Figure 21

The students double-connect the $=$ object to the + object

Figure 22

The students connect the $=$ object to the result

Figure 23

The flag displays false 


\author{
Revisions Log \\ Connecting the Equals Sign - I. Jones; D. Pratt \\ IJCO75
}

The reviewers' recommendations have been adopted to both the letter and the spirit in which they were given. Initially this involved small changes but increasingly we realised a need for larger changes in order to achieve coherency and to fully embrace the recommendations. The following is a section by section break down of the revised paper.

KEY: Editor (Ed); Reviewer 1 (R1); Reviewer 2 (R2)

FORMAT: Bold text - recommendation (recommender); Normal text - revision (page \#)

ABSTRACT
Redrafted in accordance with revisions logged below (p.1).
INTRODUCTION
• consider technologically supported uses of = (Ed, R2): meanings of $=$ in arithmetic,
algebra and technology included (p.2)

\title{
CHILDREN'S PERCEPTIONS OF THE EQUALS SIGN
}

- a greater breath, subtlety, complexity, nuance in the lit review than 'operator vs. relation' (Ed, R1, R2): Lit review significantly revised (p.3-10) including more thorough discussion of Behr et al.'s seminal paper (p.3-4); disparities between authors (p.4-5); richer meanings of = and equivalence (p.5-7); cultural issues (p.7-8); cognitive issues (p.8); relevance theory (p.9-10).

- suggested sources (R1, R2): Theis (p.4,8); Carpenter \& Levi (p.4); Yerushalmy (p.10); Baroody \& Ginsburg (p.5-6,7,9). Note some suggestions had been included in original; others were not available to us. Sources not suggested by reviewers now included are Filloy \& Rojano (p.9); Gray \& Tall (p.33); Hewitt (p.2,7,10); Jones (7,11); Knuth et al. (p.9); Piaget (p.6); Wilson \& Sperber (p.9)

$\bullet+-\times \div$ not necessarily operations (Ed): comment removed

- reading = as "makes" or "leaves" is trivial $(\mathbf{E d})$ : comment removed

- what was "performance" in McNeil's study (Ed): comment removed

- "more useful" preferable to "given higher priority" (Ed): relevance theory drawn upon (p.9-10)

- 3 typos (R1): corrected/removed

\section{APPROACH}

- explain design and intent of system with greater care (Ed, R2): description of microworld redrafted with greater attention to audience (p.13-17)

- meaning of = in the microworld (Ed, R2): function of = object explicated (p.17)

- "what was to be gained by going graphical (boxes, arrows etc)" (R2): value of 
onscreen quasi-concrete interactive objects clarified (p.13-14)

- confusion over objects" "connections" and "ports" (R2): nature of inputs (p.14) and how they are made clarified (p.16)

\section{FINDINGS ON INTERACTIONS WITH THE EQUALS SIGN}

- more data from same trial or from other trials (Ed, R1, R2): more data from earlier and later in the same trial included (p.19-21,28-29); other trial data is not available to the authors

- expand upon the initial use of = which the students "did not interact with further" (R1): done (p.19-21)

- enlarge student sample (R1, R2): larger sample of data not available to the authors

- "L attended to algorithmic knowledge" is an unsupported assertion (R1): comment removed

- typo (R1): corrected

- what does the connection arrow mean for the students? (R1): students' initial experience and discussion of making connections included (p.19)

- students use of discussion of equation as "circuit" implies a data-flow conception (R2): incorporated into data description (p.22,23,25,27)

\section{DISCUSSION}

- more subtlety and complexity to analysis of meanings of = $(\mathrm{ED}, \mathrm{R} 1, \mathrm{R2})$ : discussion section substantially reorganised to discuss data in terms of the literature review (p.30-35)

- topological "data-flow" conceptions apparent (R2): incorporated into discussion (p.32-33)

- make less explicit statements about computational utilities of $=$ as servicing traditional meanings of $=(\mathbf{R 2})$ : comments removed

- researcher asks a leading question and authors draw an unwarranted conclusion (R1): leading nature of question acknowledged and conclusion toned down (p.34)

CLOSING COMMENT

N/A 
Click here to download high resolution image

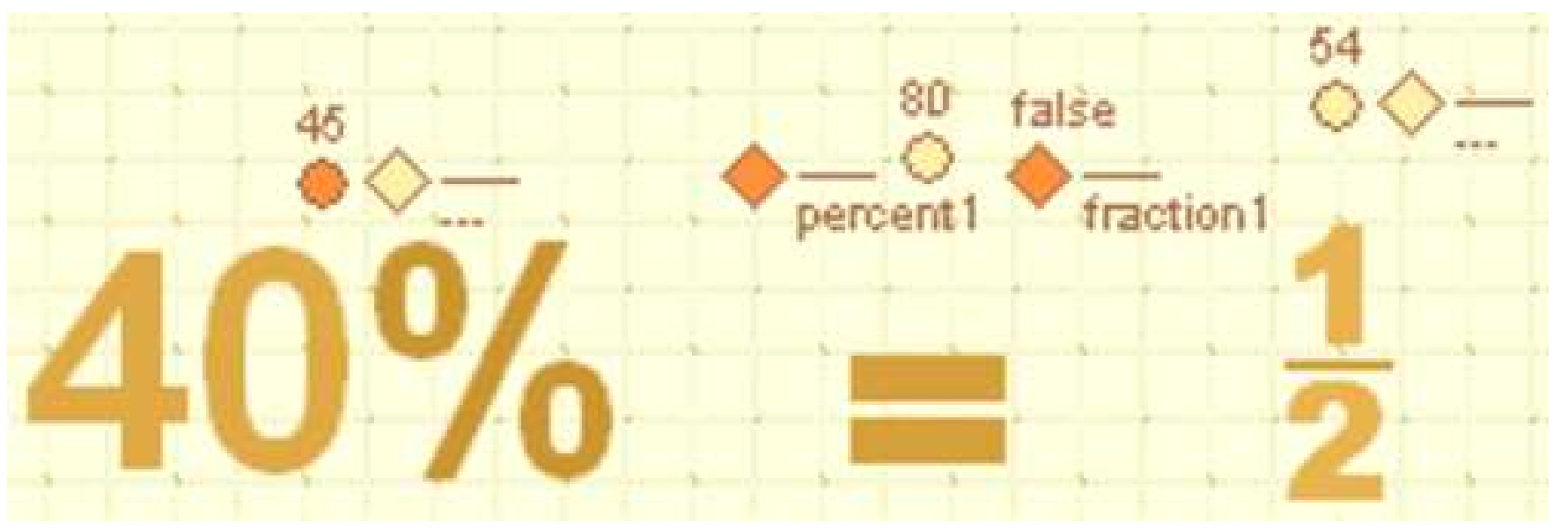


Click here to download high resolution image

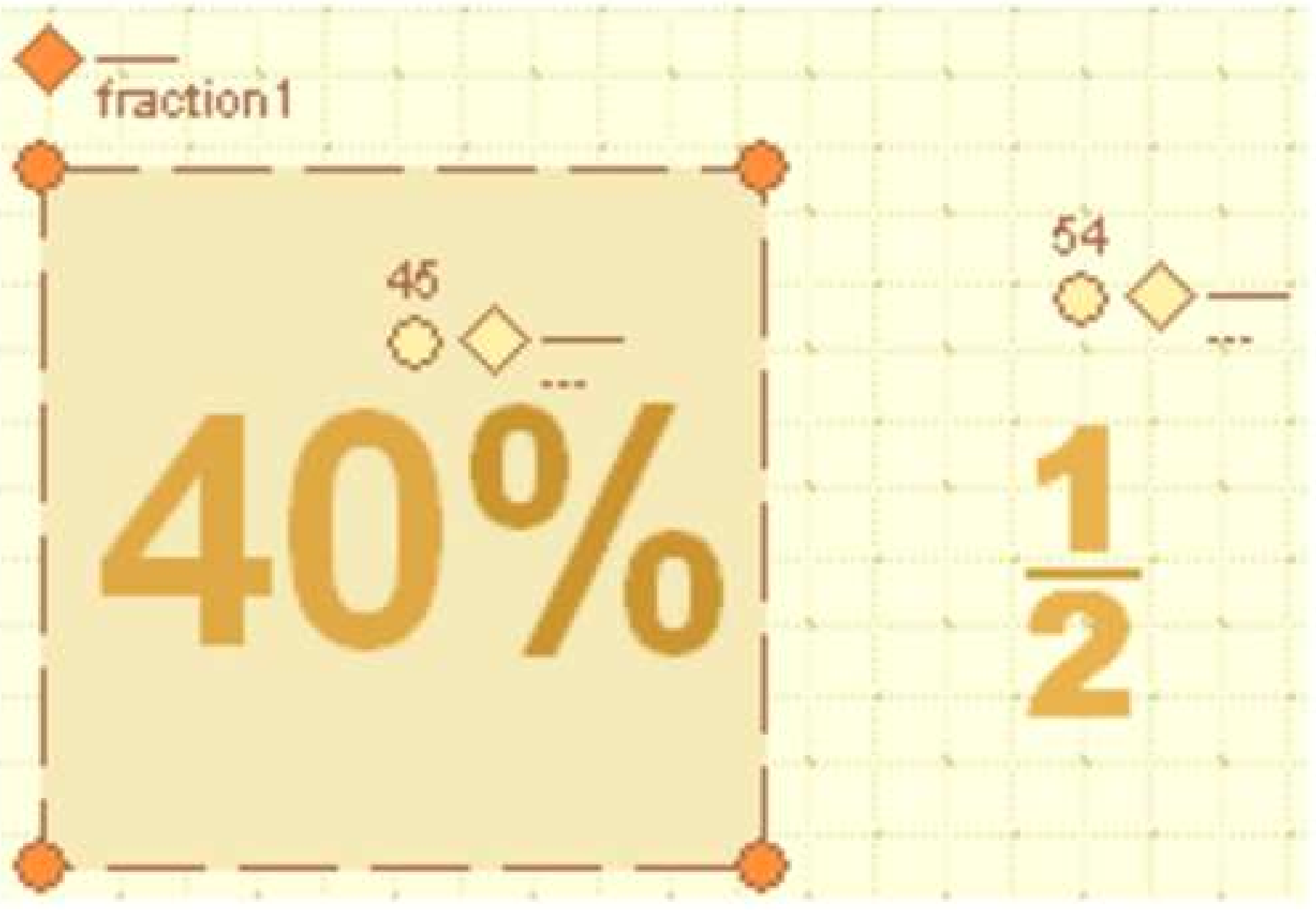


Click here to download high resolution image

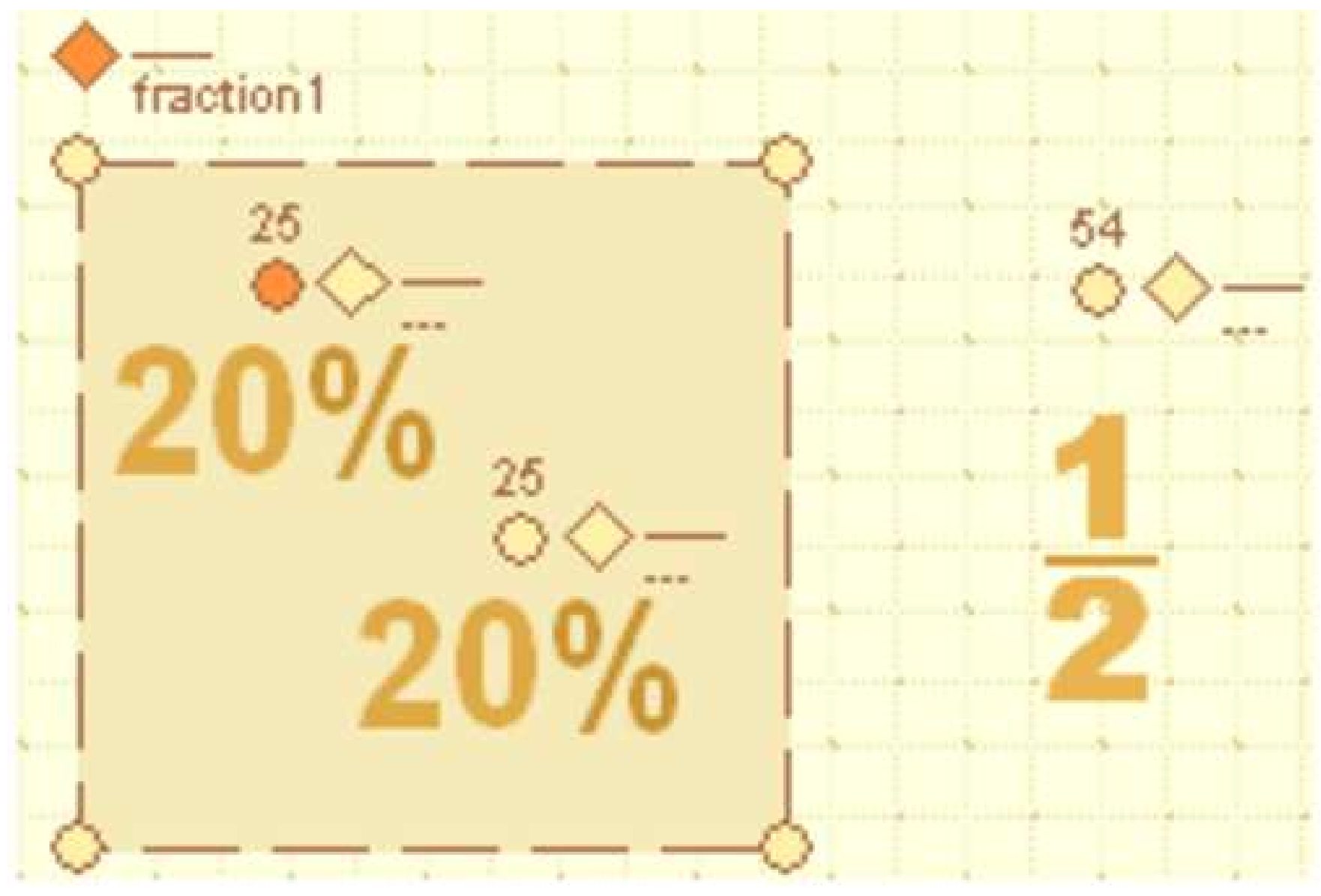


Click here to download high resolution image

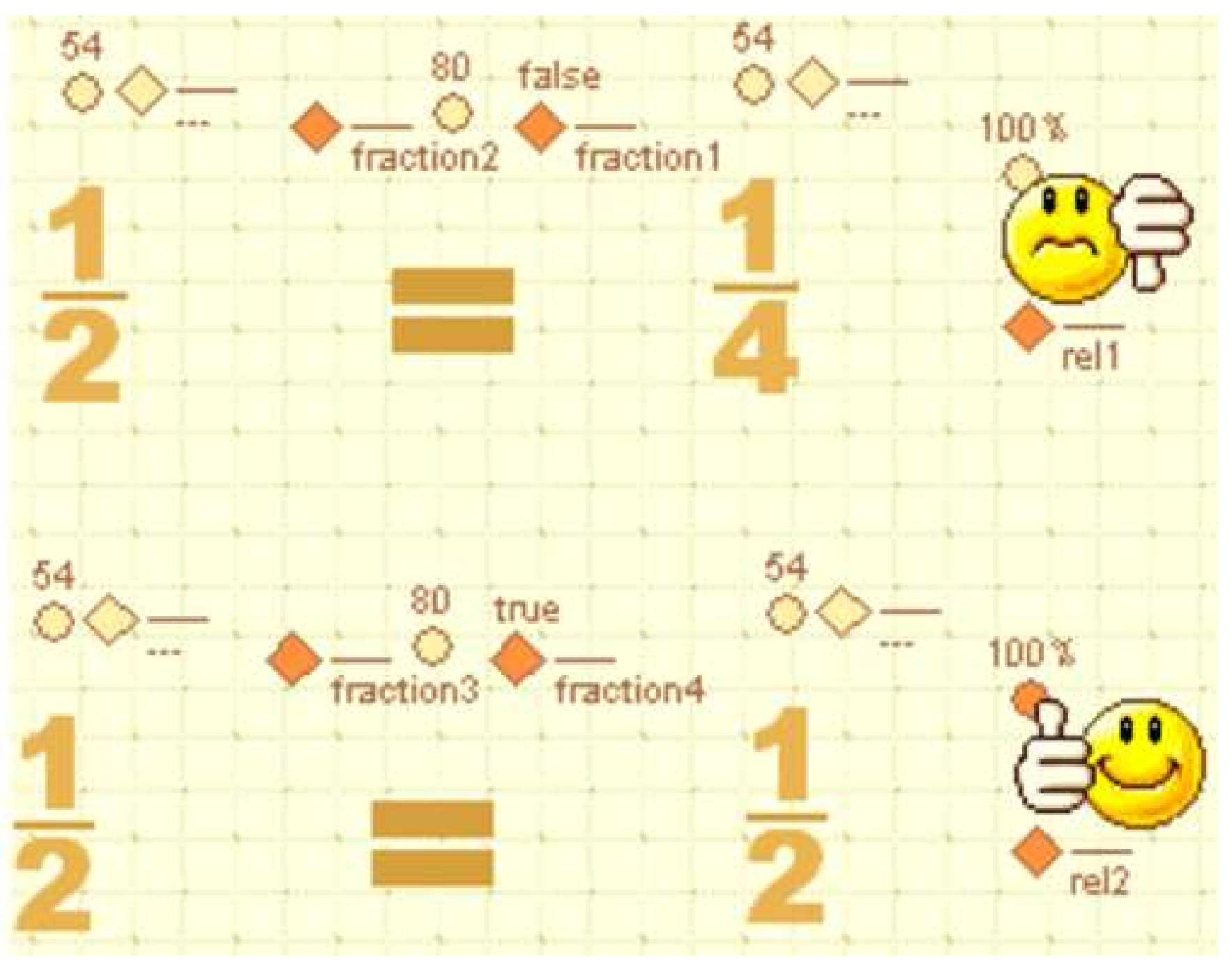


Click here to download high resolution image

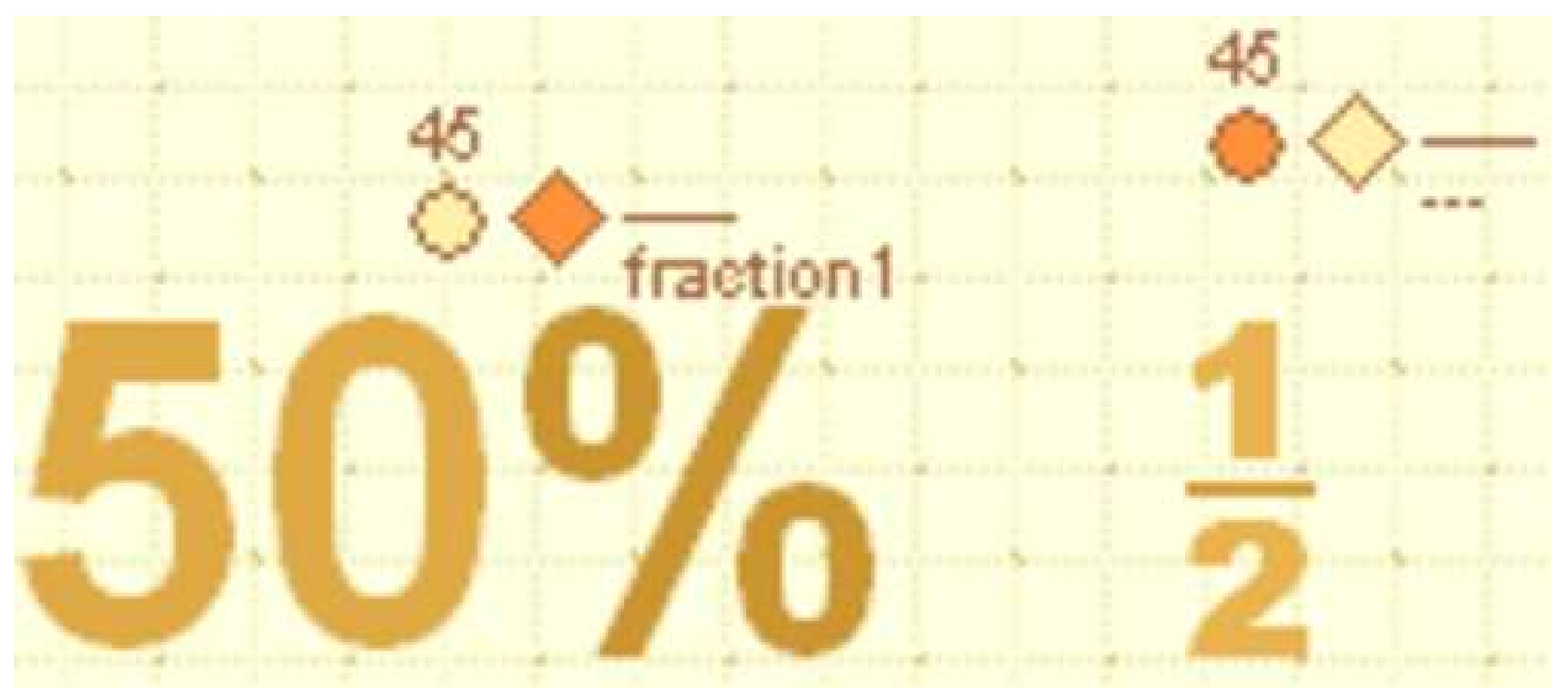


Click here to download high resolution image

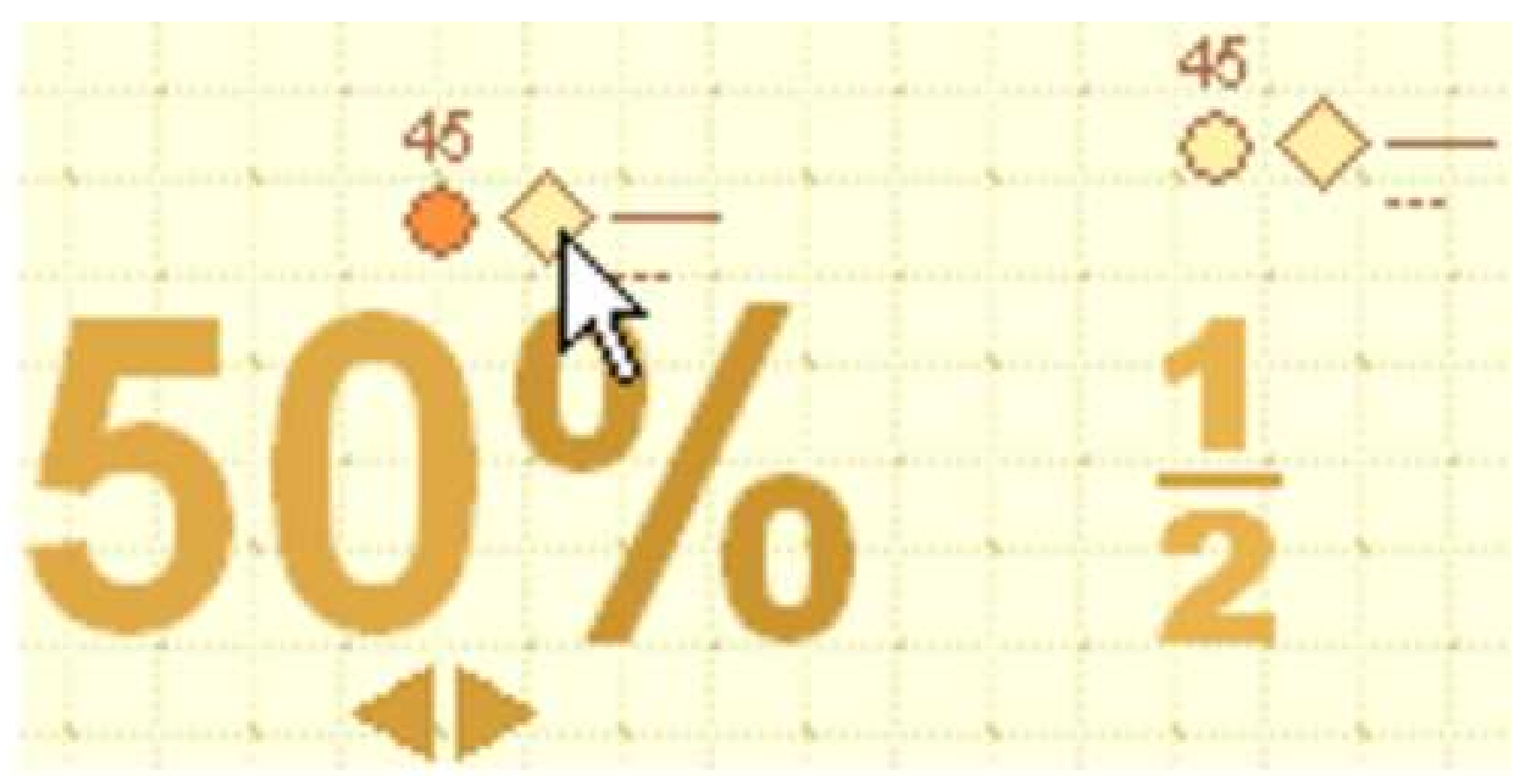


Click here to download high resolution image

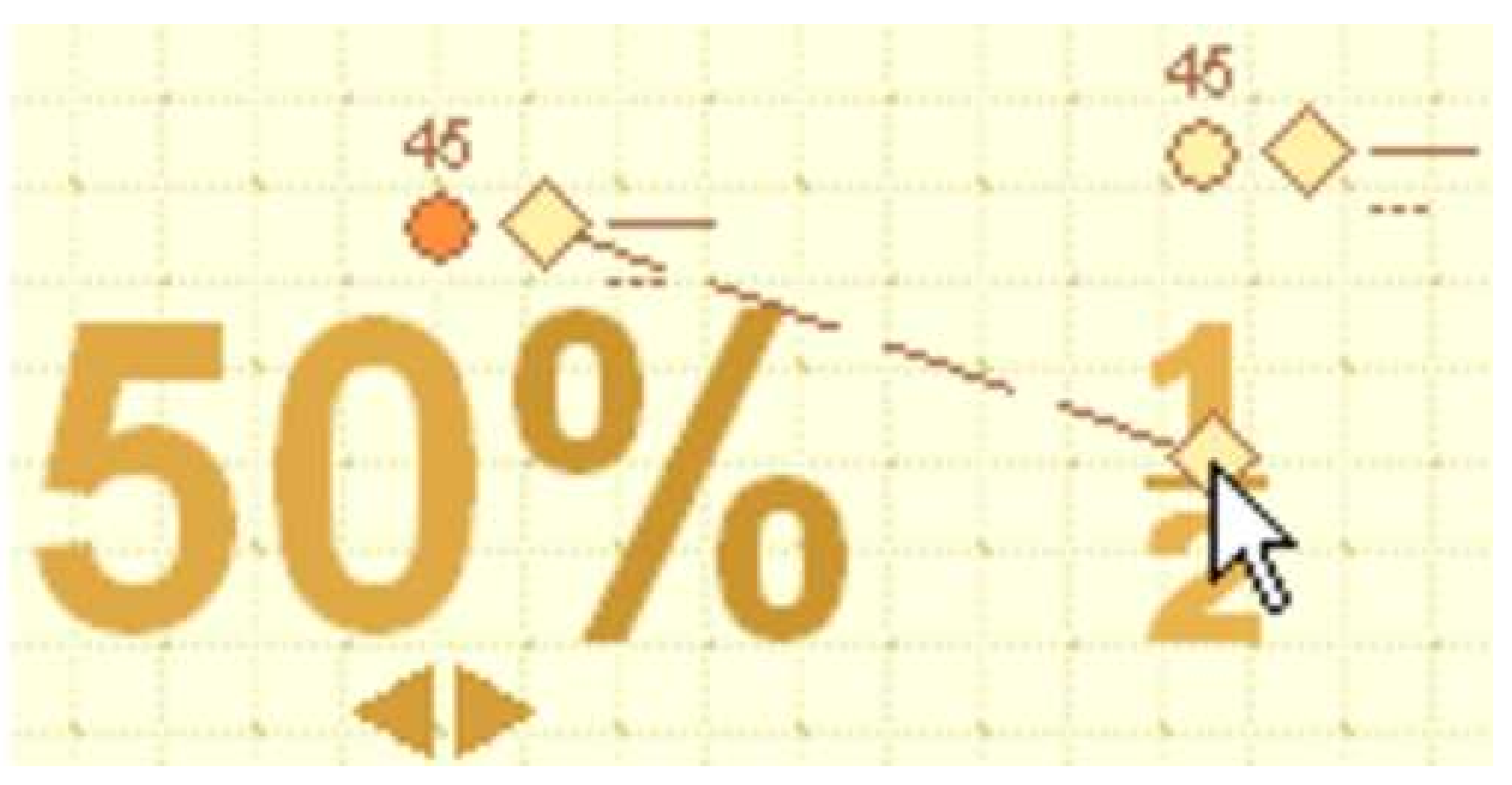


Click here to download high resolution image

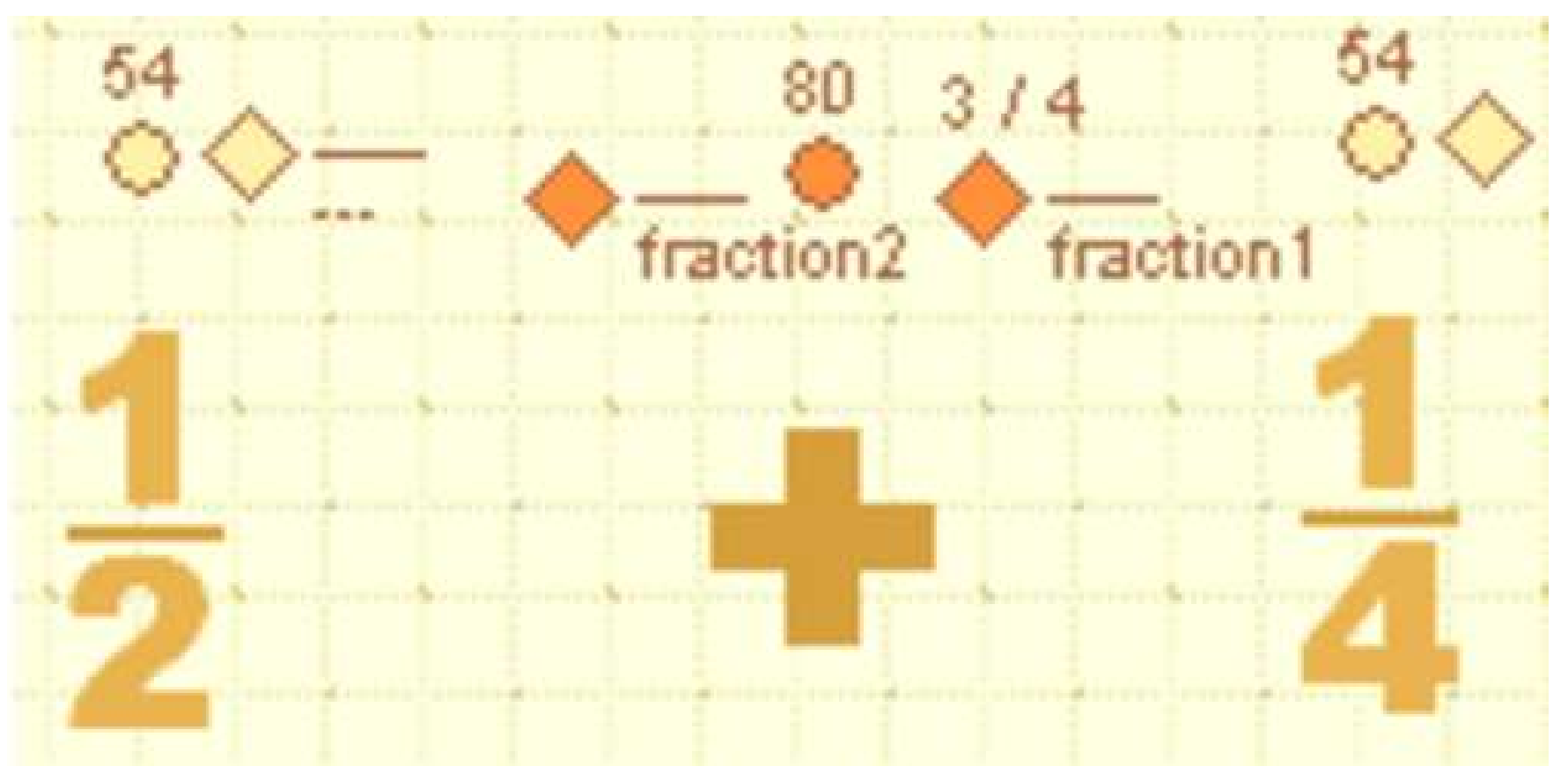


Click here to download high resolution image

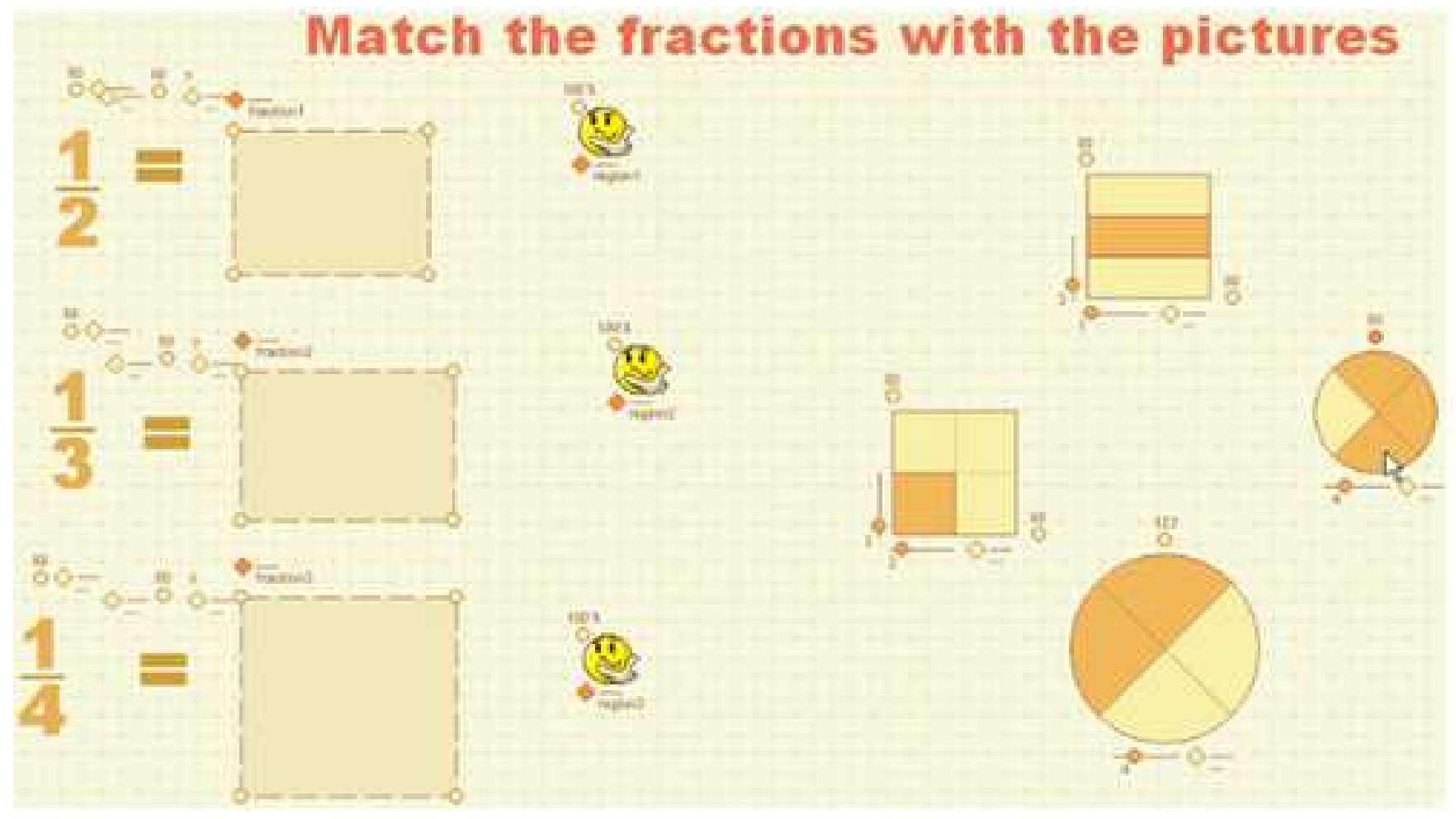


Click here to download high resolution image

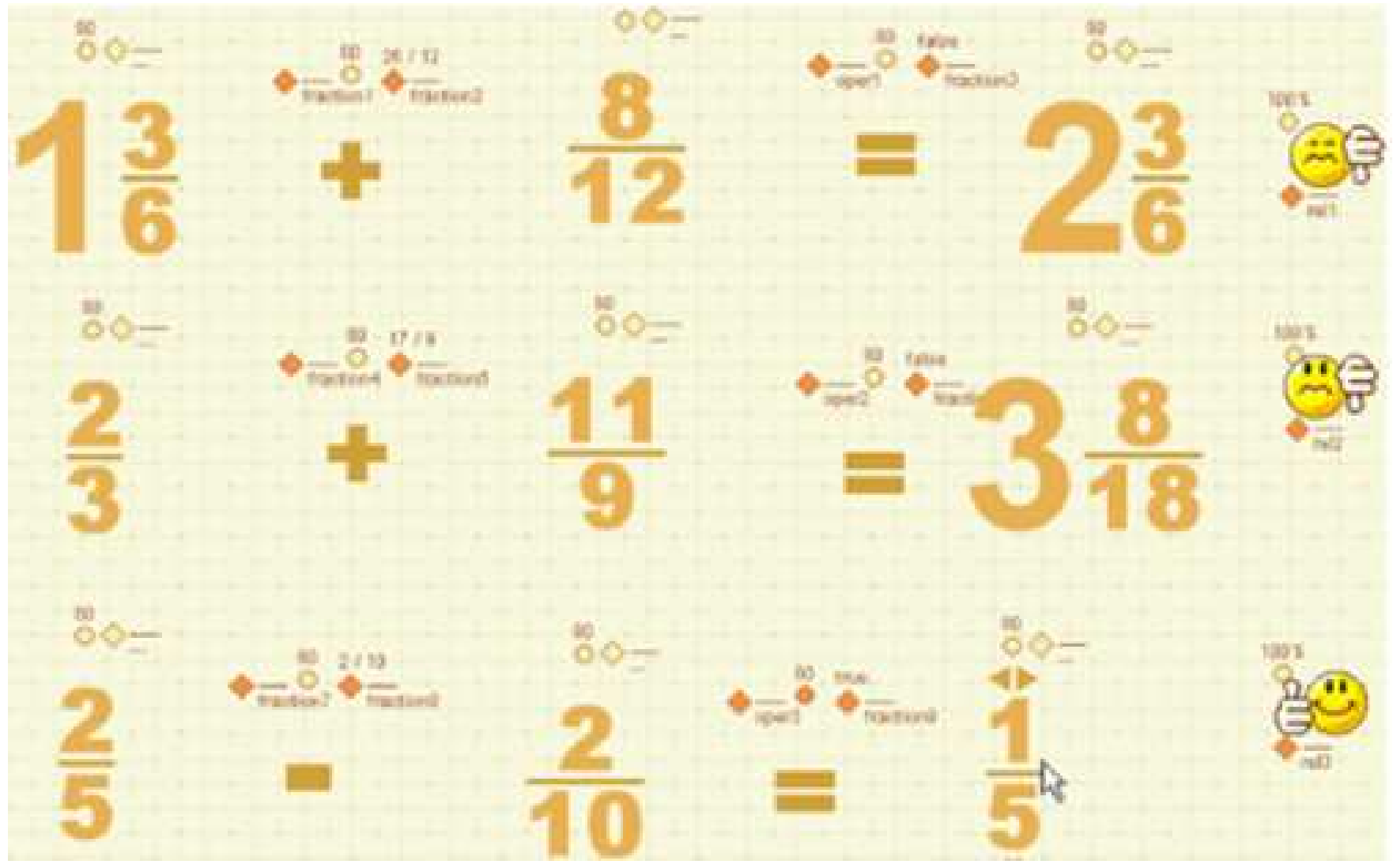


Click here to download high resolution image

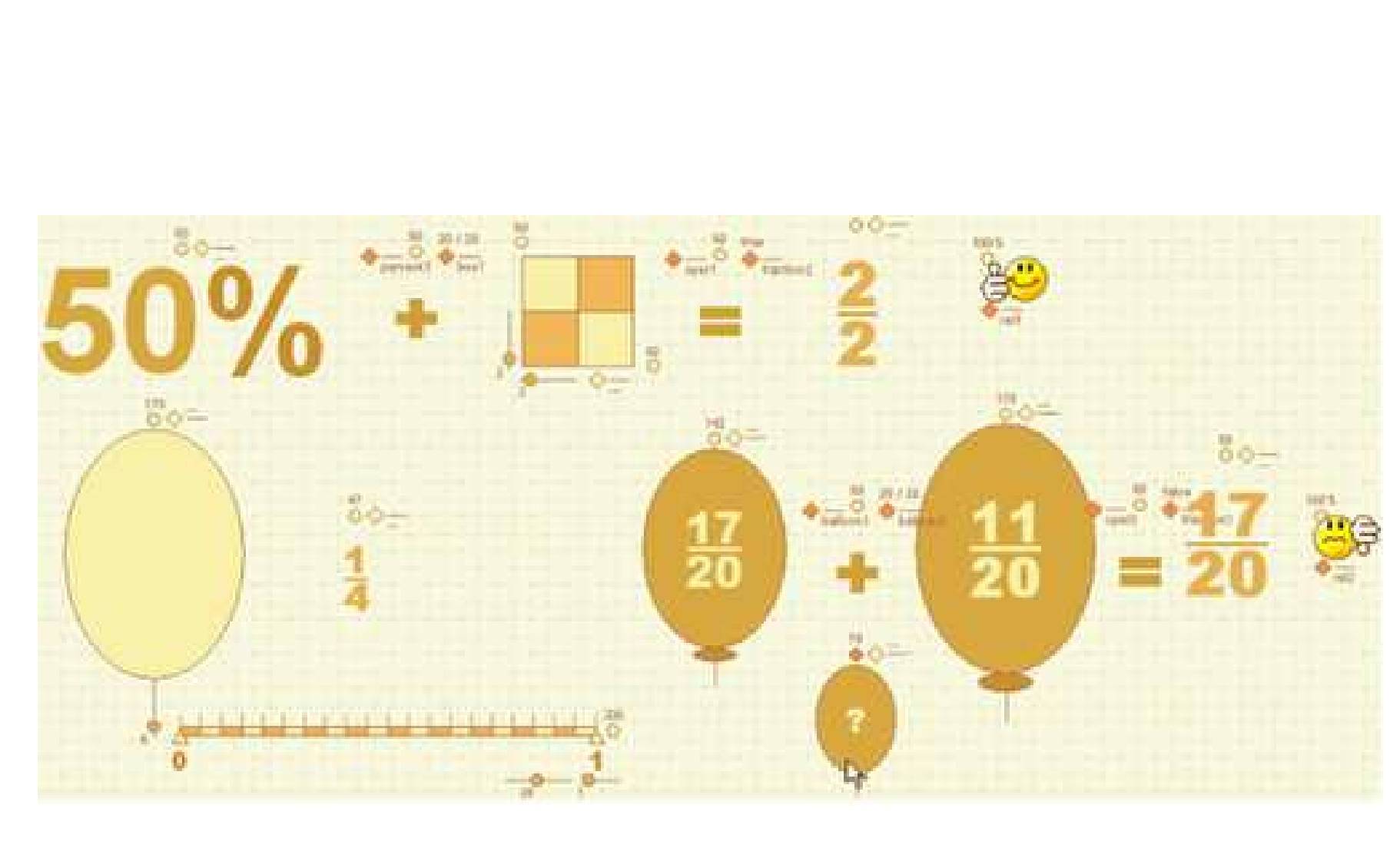
colour figure
Click here to

. 
Click here to download high resolution image

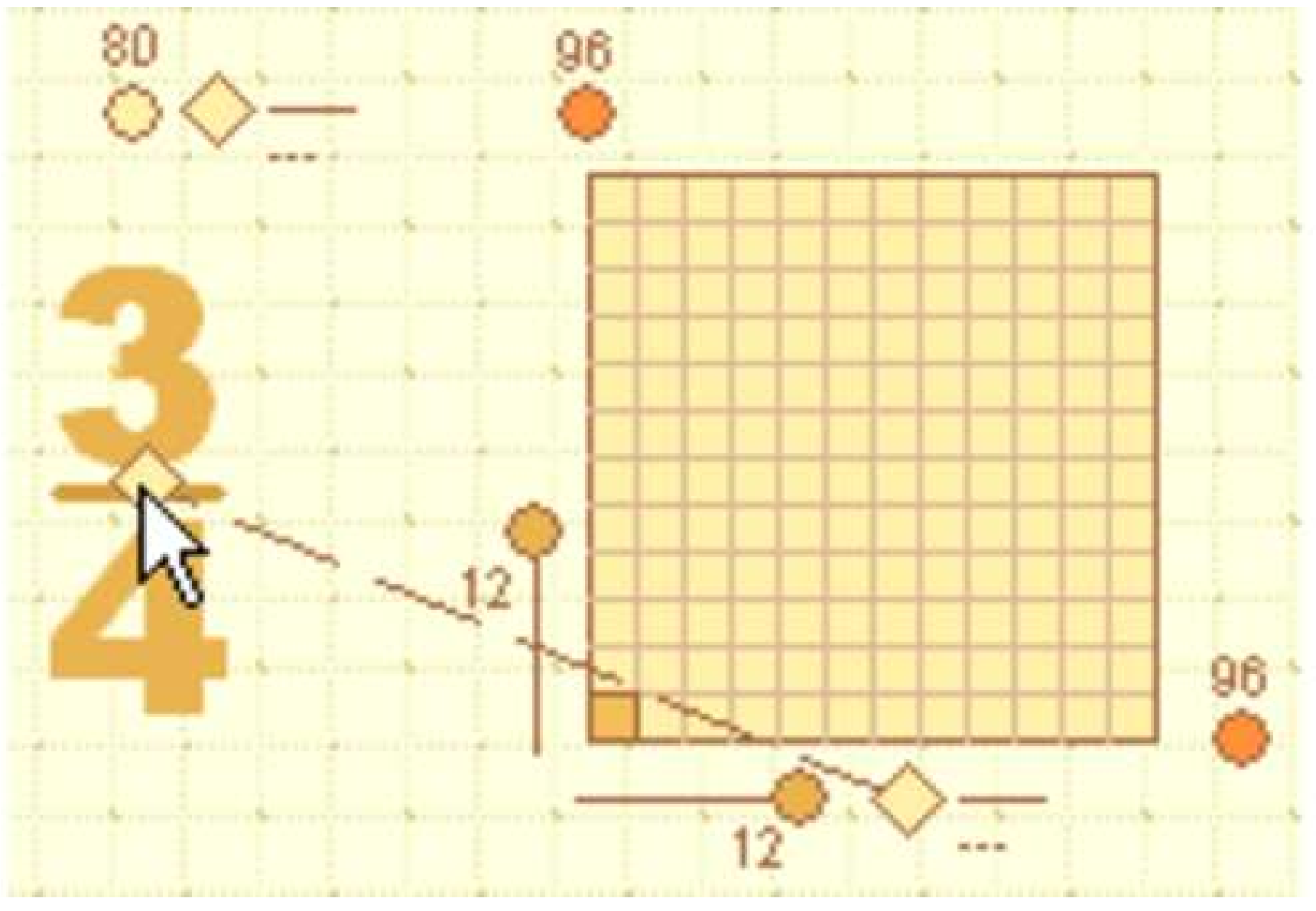


Click here to download high resolution image

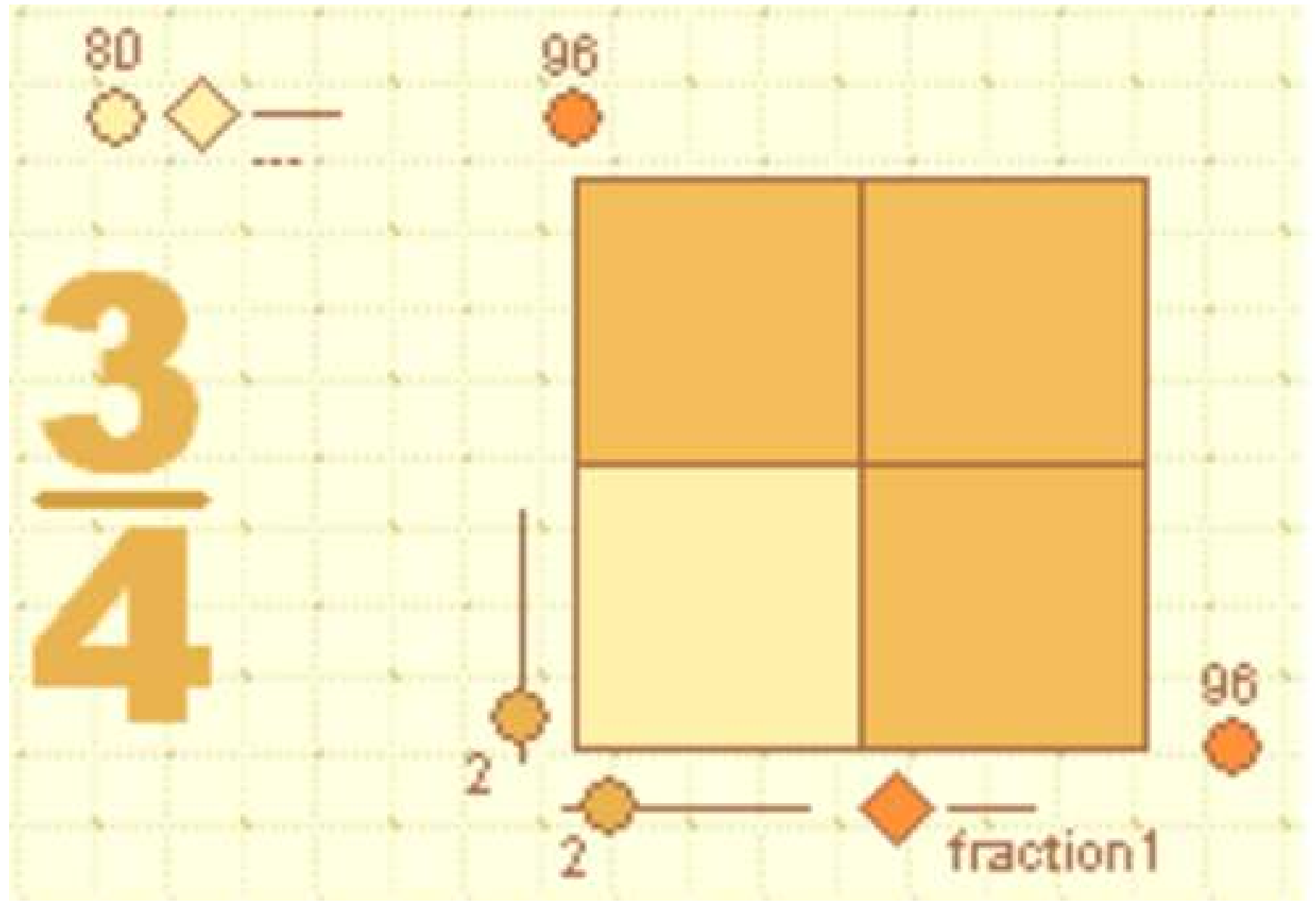


Click here to download high resolution image

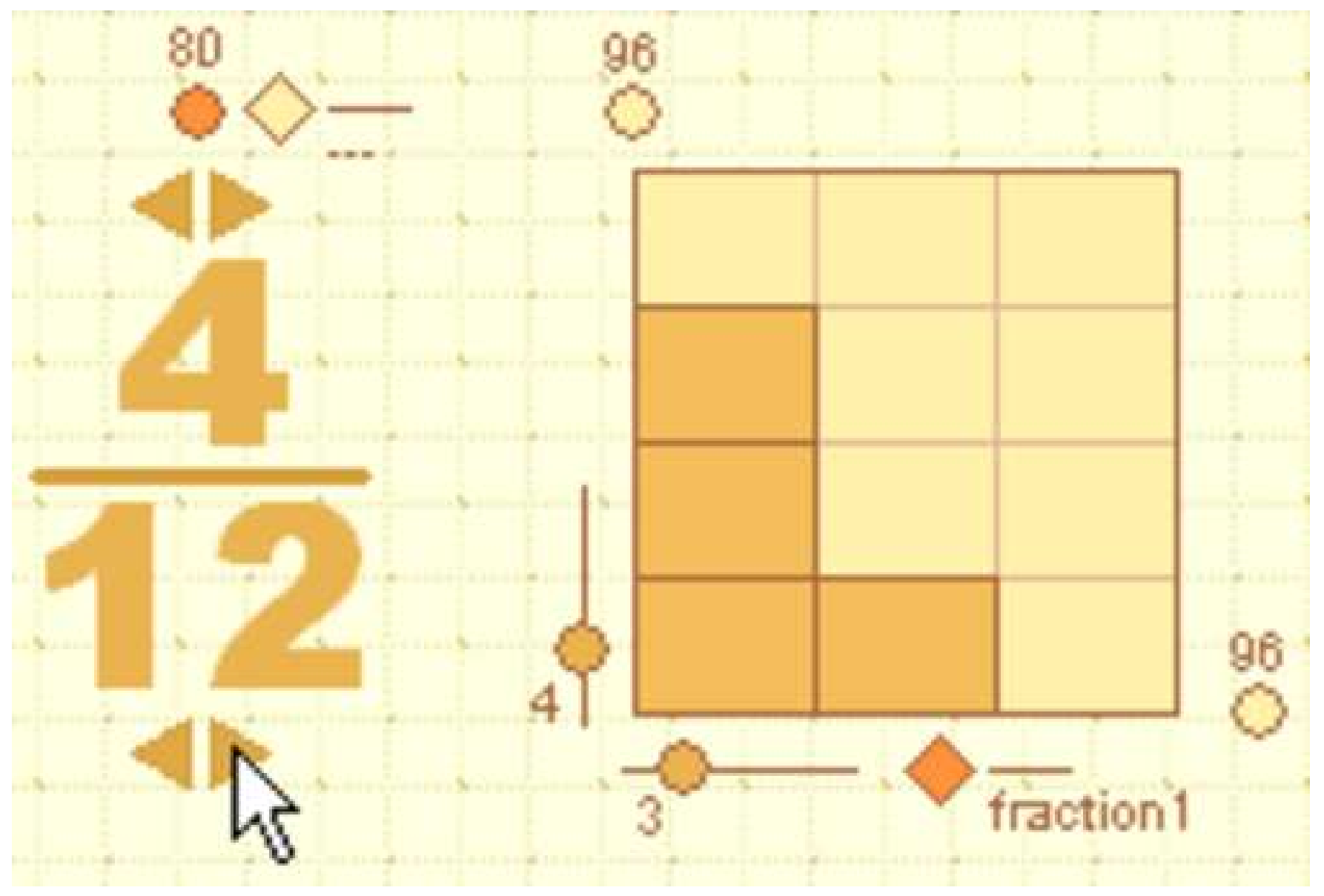


Click here to download high resolution image

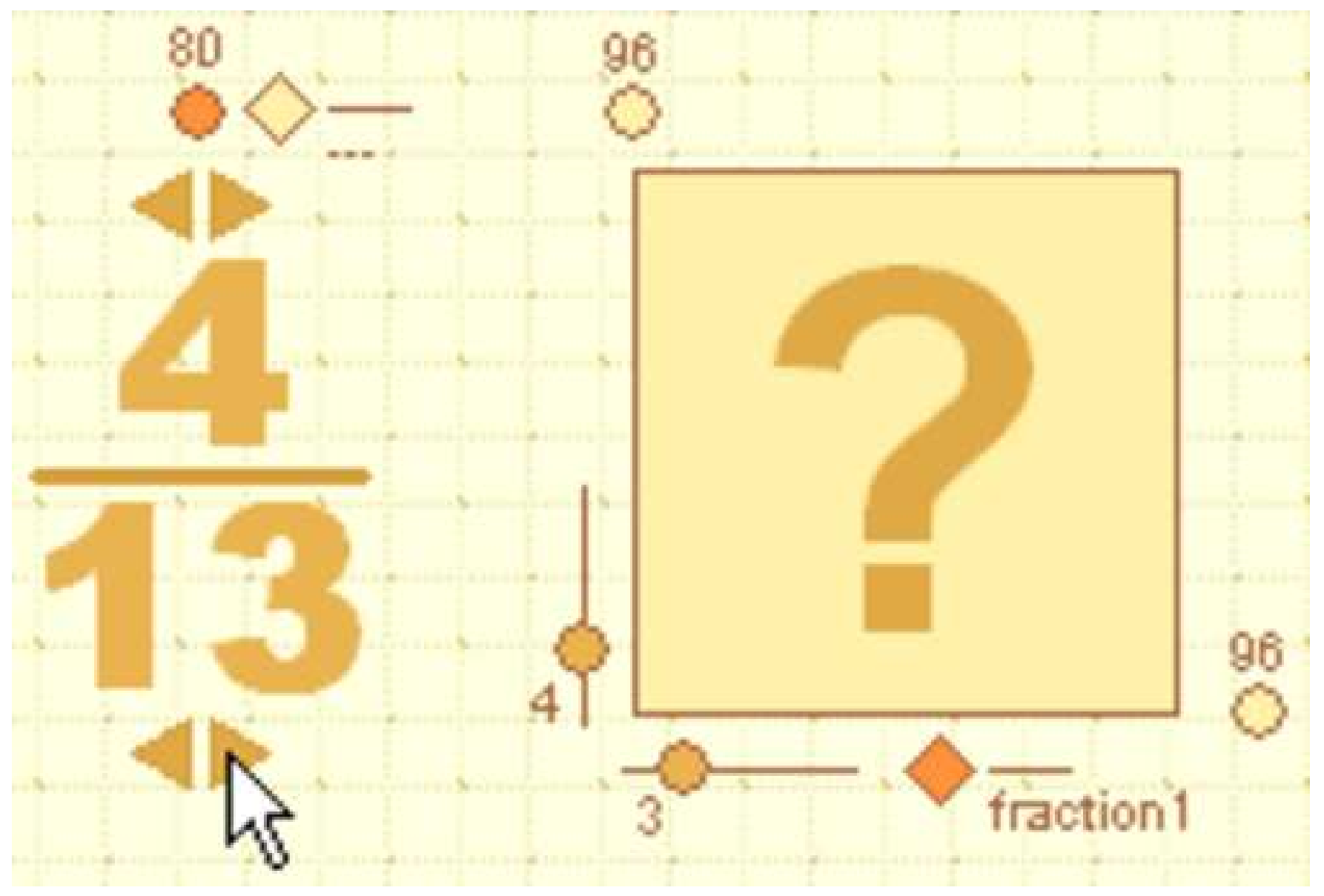


Click here to download high resolution image

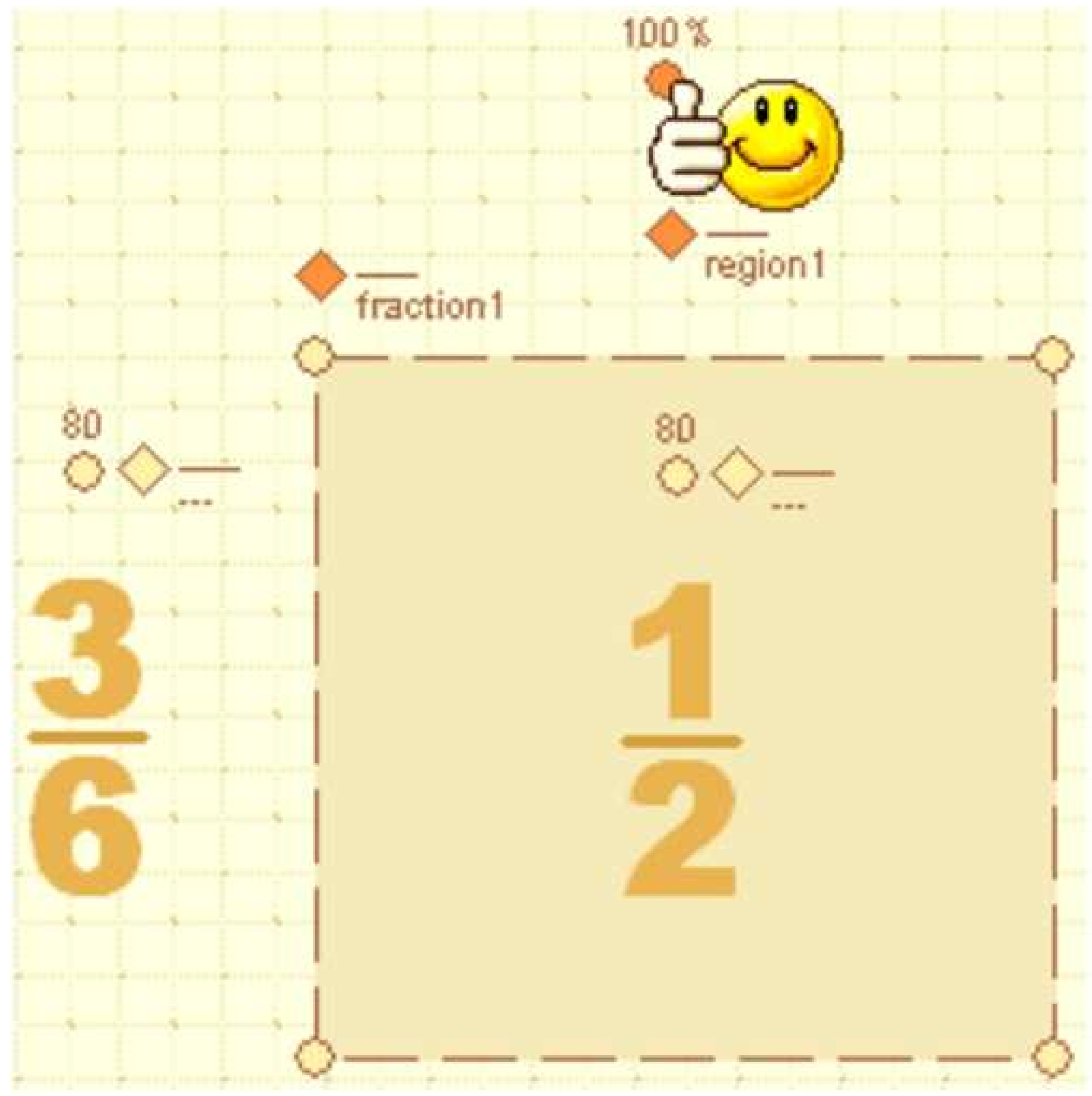


Click here to download high resolution image

\section{$100 \%$}

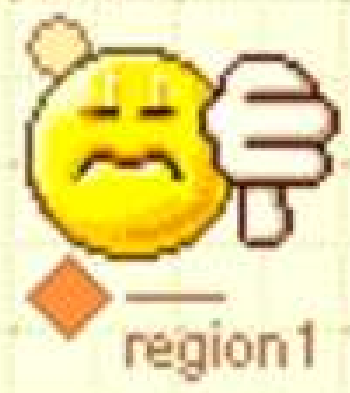

\section{fraction 1}
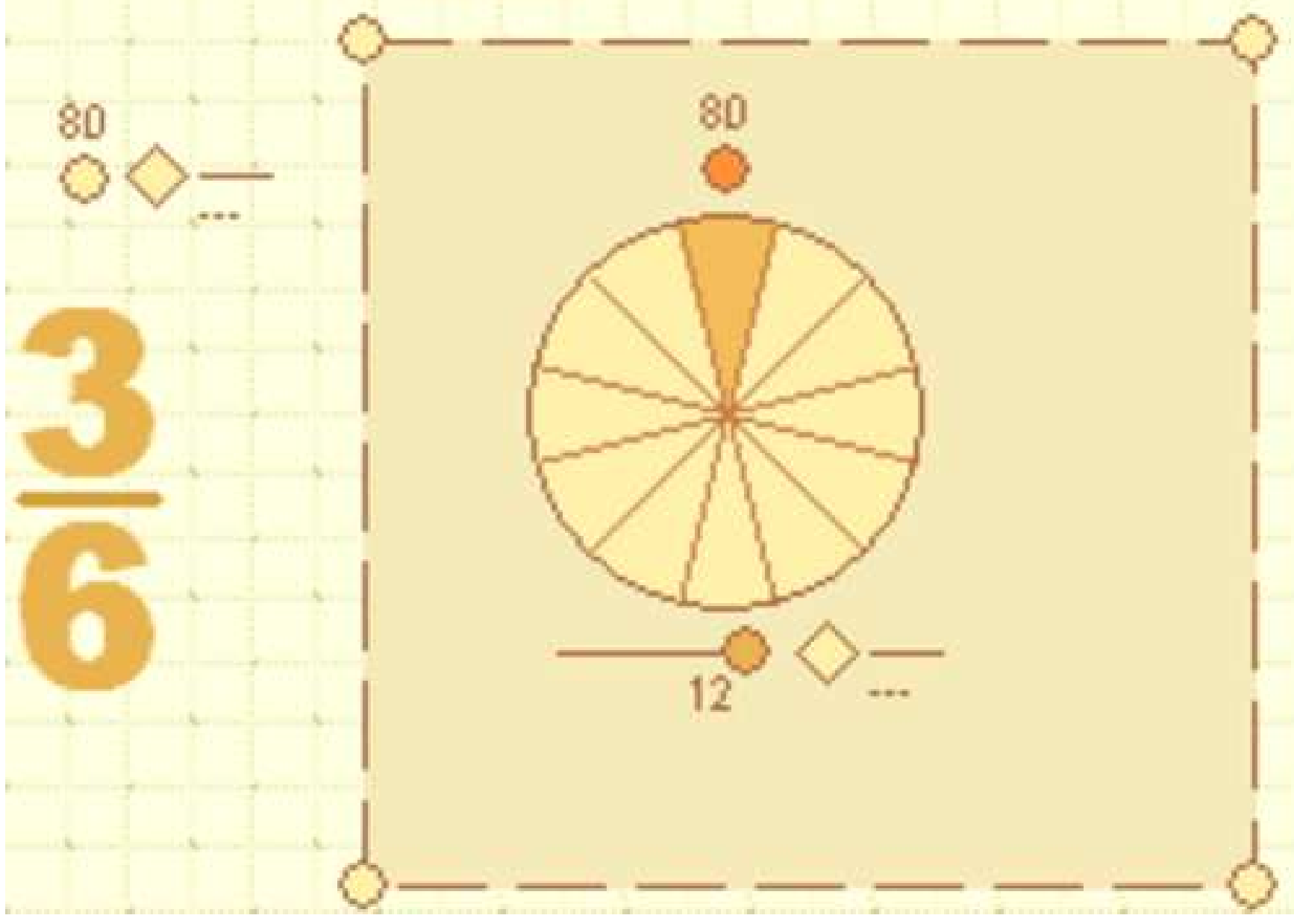
Click here to download high resolution image

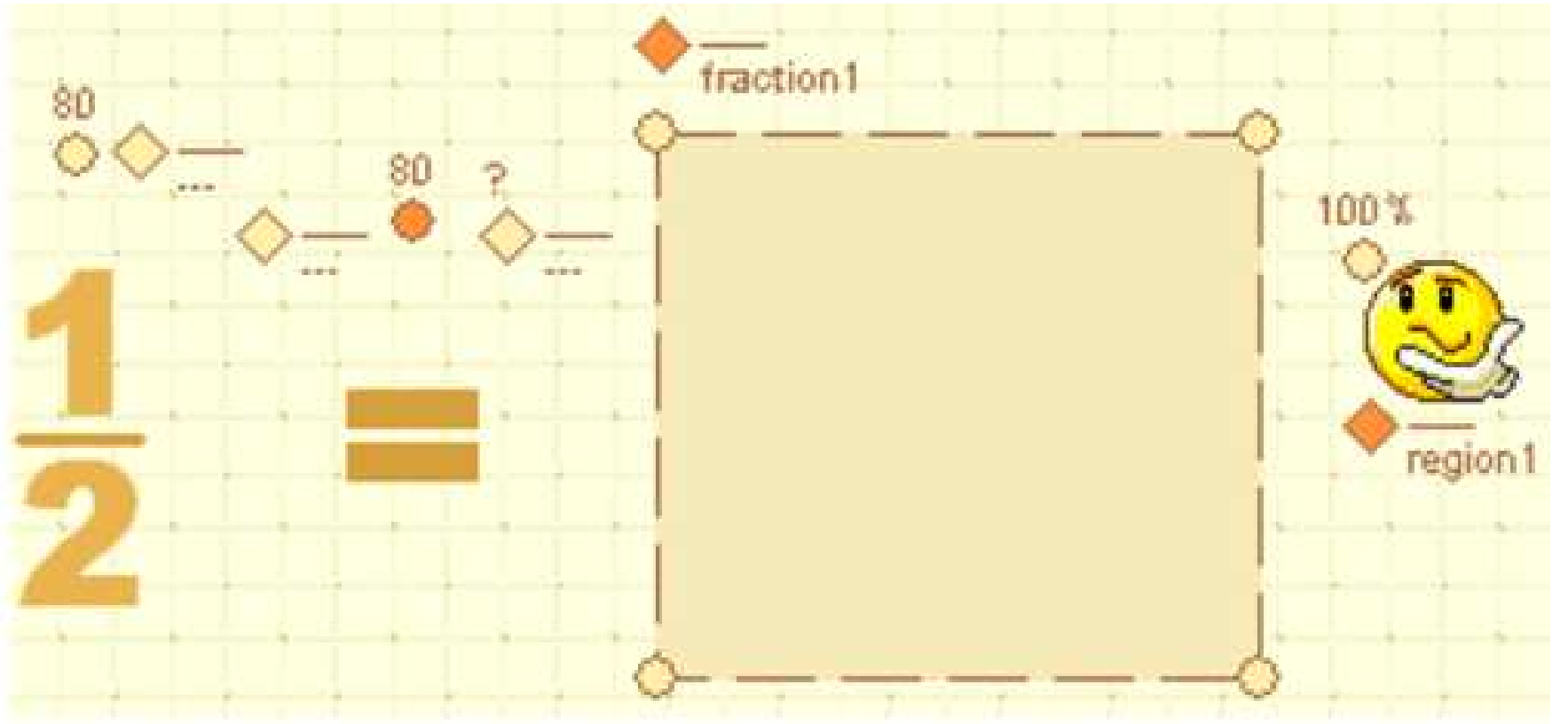


Click here to download high resolution image

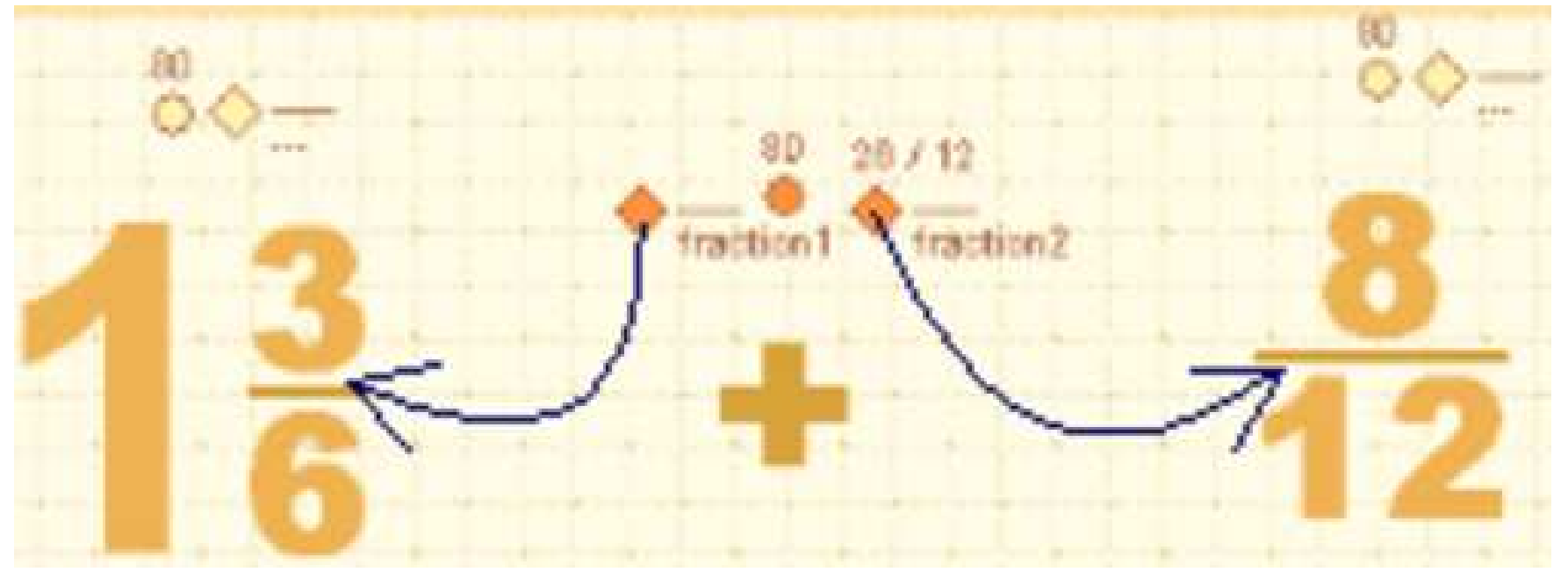


Click here to download high resolution image

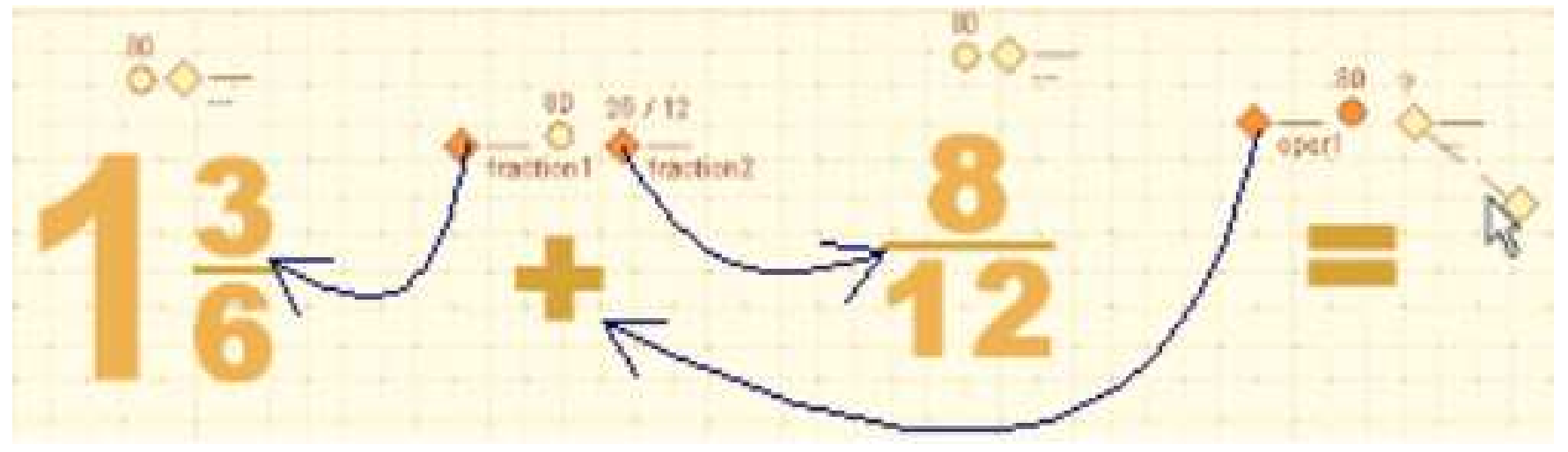


Click here to download high resolution image

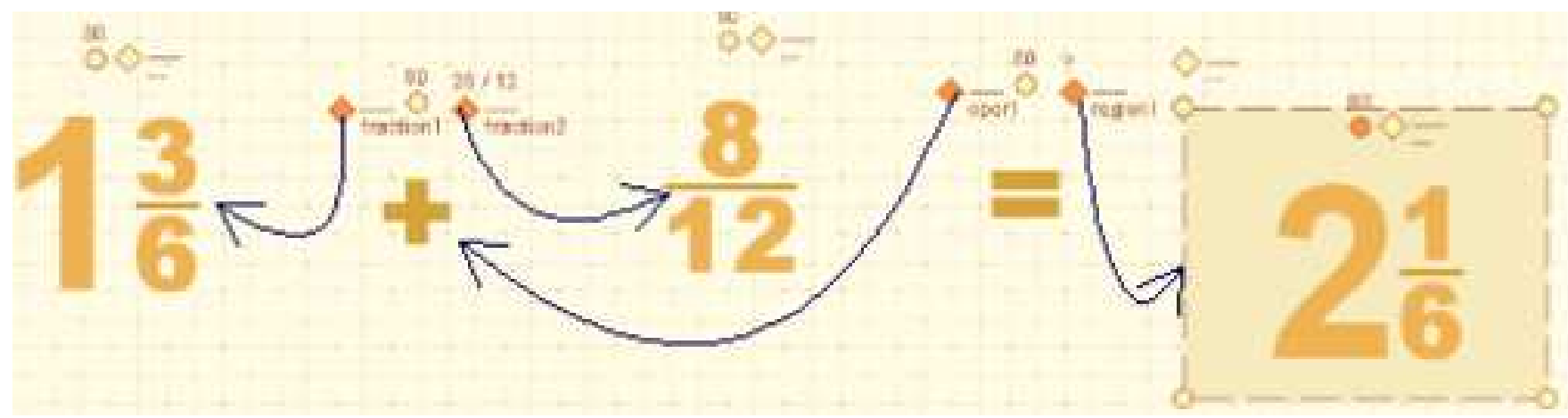


Click here to download high resolution image

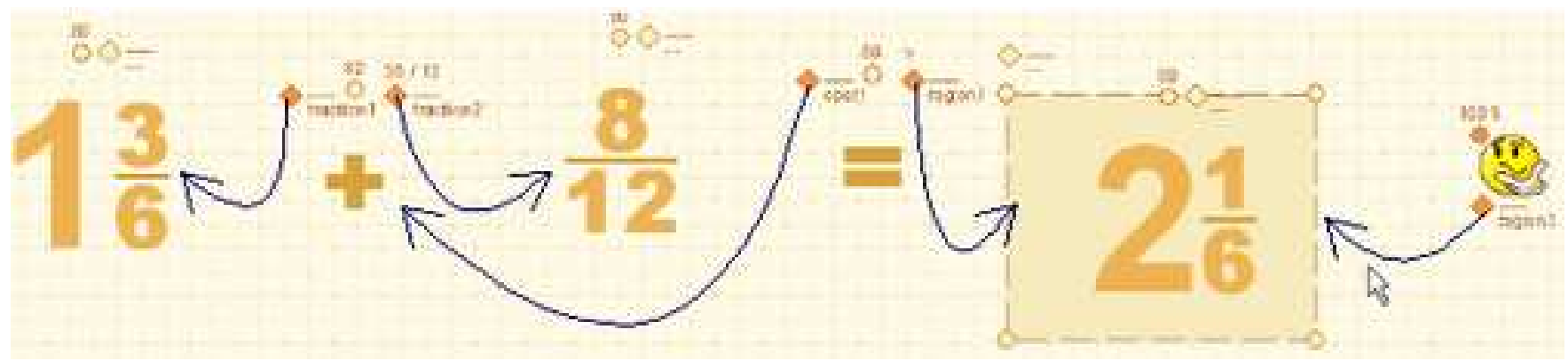


Click here to download high resolution image
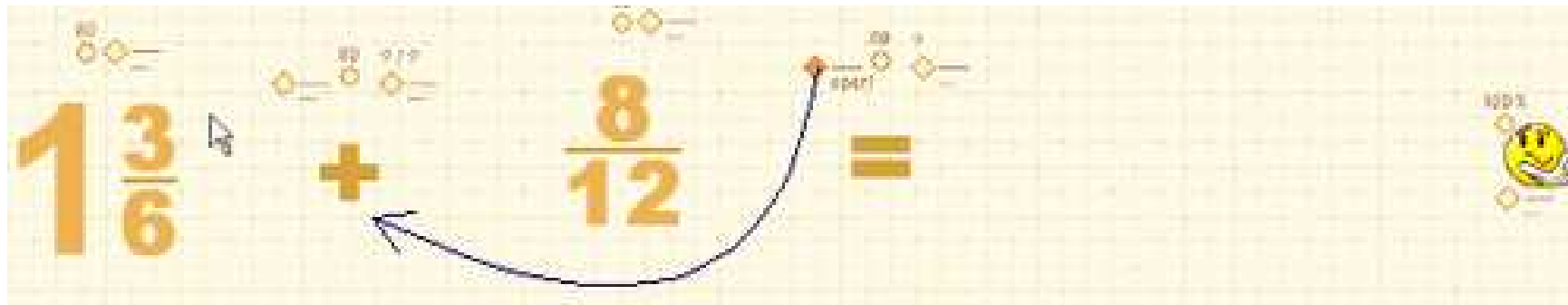
Click here to download high resolution image

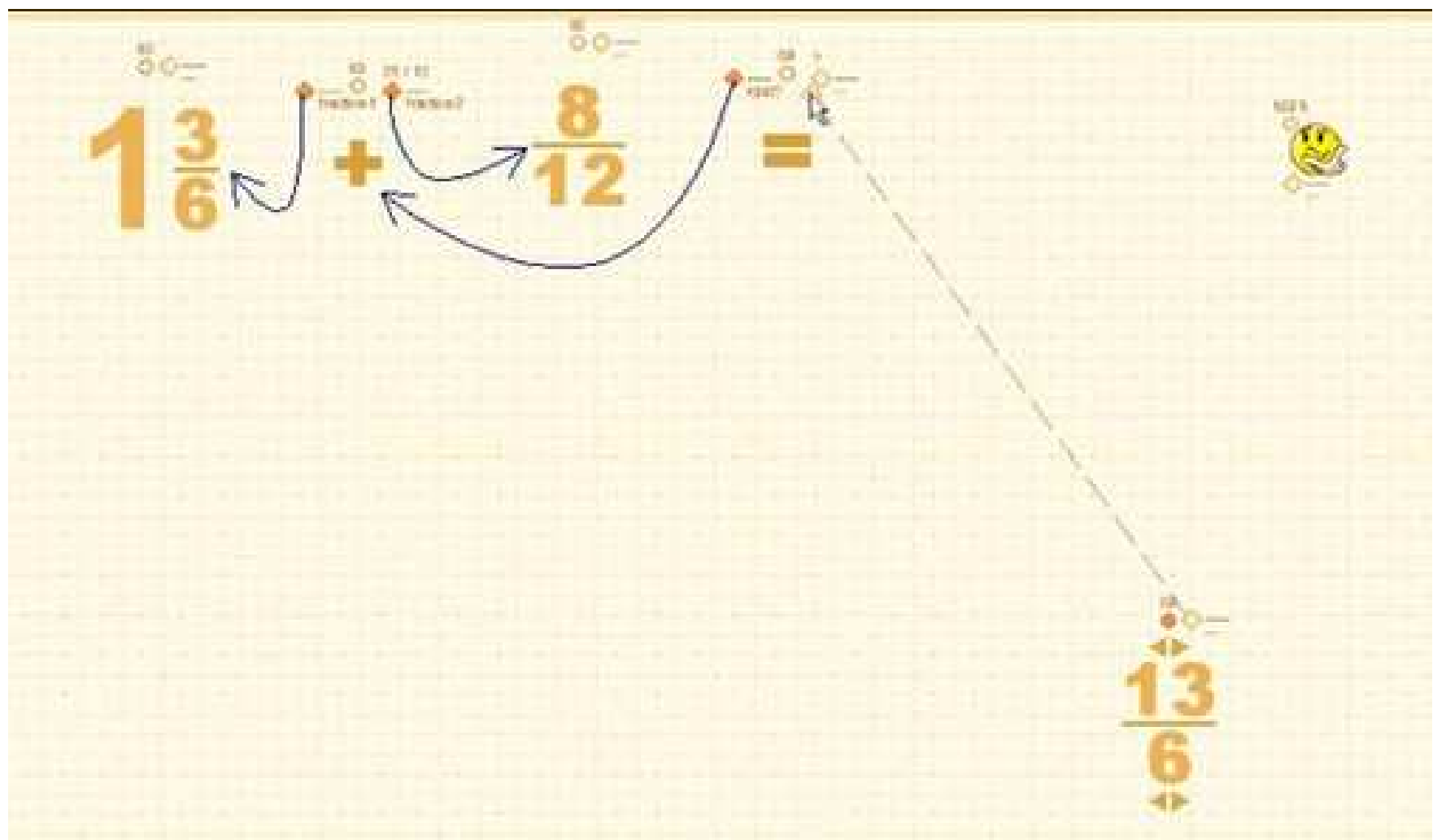


Click here to download high resolution image

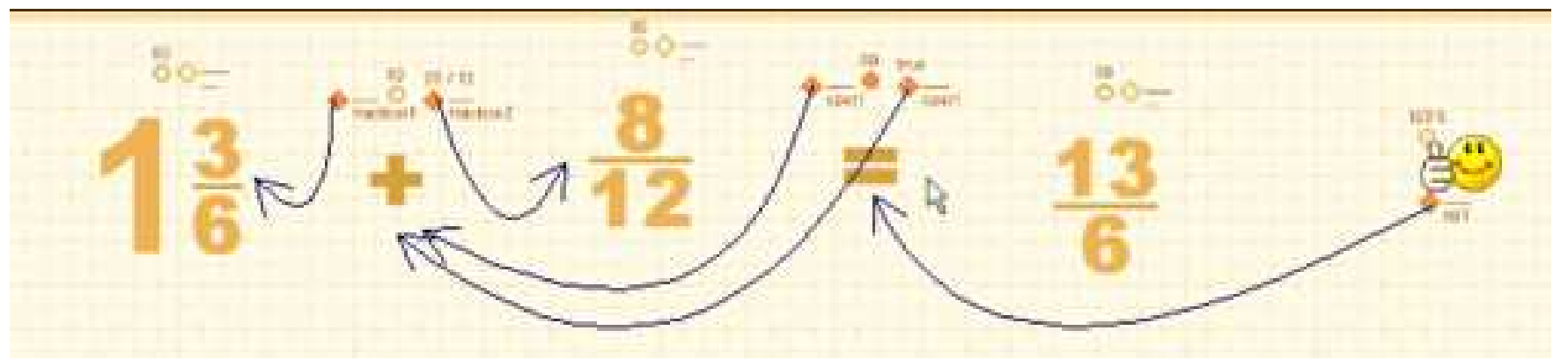


Click here to download high resolution image

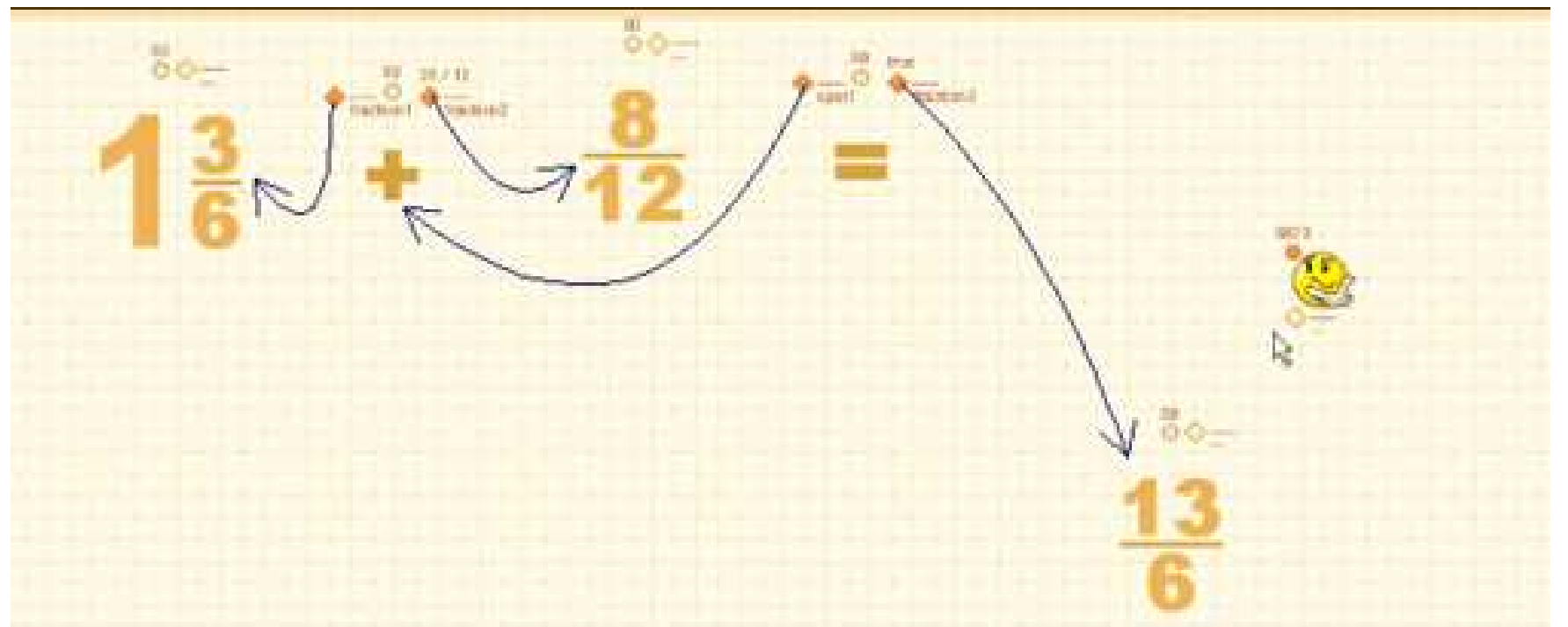


Click here to download high resolution image

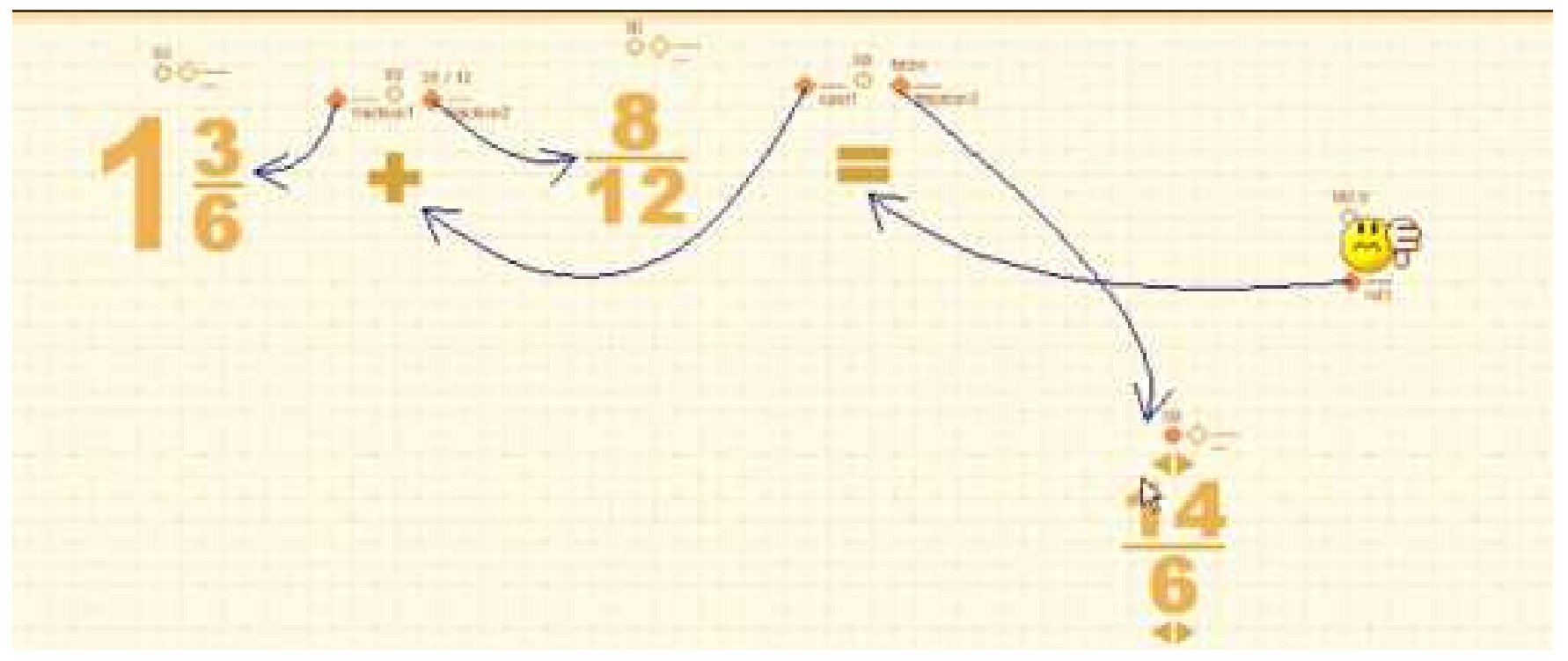

